\title{
Three-Phase Borate Solid Solution With Low Sintering Temperature, High Quality Factor, and Low Dielectric Constant: Experimental and DFT Study
}

\section{Rui Peng}

University of Electronic Science and Technology of China https://orcid.org/0000-0002-9497-7108

Hua Su (D uestcsh77@163.com )

University of Electronic Science and Technology of China

Yuanxun Li ( $\square$ liyuanxun@uestc.edu.cn )

University of Electronic Science and Technology of China

Yongcheng Lu

University of Electronic Science and Technology of China

\section{Liang Shi}

University of Electronic Science and Technology of China

Wei Du

University of Electronic Science and Technology of China

Xiaoli Tang

University of Electronic Science and Technology of China

Guoliang Yu

China Jiliang University

Minshu Chen

Nanjing University of Information Science and Technology

\section{Research Article}

Keywords: LTCC, Dielectric properties, DFT, Borate, Solid solutions

Posted Date: November 3rd, 2020

DOI: https://doi.org/10.21203/rs.3.rs-99564/v1

License: (c) (i) This work is licensed under a Creative Commons Attribution 4.0 International License.

Read Full License 
Three-phase borate solid solution with low sintering temperature, high quality factor, and low

dielectric constant: Experimental and DFT study

Rui Peng ${ }^{\mathrm{a}}$, Hua Su ${ }^{\mathrm{a}, \mathrm{b}, *}$, Yuanxun $\mathrm{Li}^{\mathrm{a},{ }^{*}}$ Yongcheng Lu ${ }^{\mathrm{a}}$, Liang Shi ${ }^{\mathrm{a}}$, Wei Du ${ }^{\mathrm{a}}$, Xiaoli Tang ${ }^{\mathrm{a}}$, Guoliang Yu ,

Minshu Chen ${ }^{\mathrm{d}}$,

${ }^{a}$ State Key Laboratory of Electronic Thin Films and Integrated Devices, University of Electronic

Science and Technology of China, Chengdu 610054, China

b Jiangxi Guochuang Industrial Park Development Co., Ltd, Ganzhou 341000, China.

${ }^{\mathrm{c}}$ China Jiliang University, Hangzhou 310018, China.

d Nanjing University of Information Science and Technology, Nanjing 210000, China.

*e-mail: uestcsh77@163.com, liyuanxun@uestc.edu.cn

\section{Abstract}

The sintering and microwave dielectric properties of a ceramic material based on $\mathrm{Mg}^{2+}$ substituted $\mathrm{Zn}_{3} \mathrm{~B}_{2} \mathrm{O}_{6}$ have been widely studied using first principles calculations and experimental solid-state reactions. Characterization methods include the Network Analyzer, X-ray, Raman diffraction, scanning electron microscopy, energy-dispersive spectroscopy, and differential-thermal \& thermo-mechanical analyzer. The increasing amount of $\mathrm{Mg}^{2+}$ results in the appearance of $\mathrm{Mg}_{2} \mathrm{~B}_{2} \mathrm{O}_{5}$ and $\mathrm{ZnO}$, and the mutual substitution $\left(\mathrm{Mg}^{2+}\right.$ and $\left.\mathrm{Zn}^{2+}\right)$ phenomenon has emerged in $\mathrm{Zn}_{3} \mathrm{~B}_{2} \mathrm{O}_{6}$ and $\mathrm{Mg}_{2} \mathrm{~B}_{2} \mathrm{O}_{5}$. The mechanisms have been explained with the help of DFT calculations. The bond parameters and electron distributions of the $\mathrm{ZnO}_{4}$ tetrahedron and the $\mathrm{MgO}_{6}$ octahedron have been modified due to substitution. The sintering, substitution, and phase formation properties have been analyzed quantitatively through the energy parameters. The best dielectric properties were obtained for $\mathrm{x}=0.20$ sintered at $950^{\circ} \mathrm{C}$, 
$\varepsilon_{r}=6.47, Q \times f=89,600 \mathrm{GHz}(15.2 \mathrm{GHz}), \tau_{f}=-48.6 \mathrm{ppm} /{ }^{\circ} \mathrm{C}$, relative density $=96.7 \%$. The substitution of $\mathrm{Mg}^{2+}$ to $\mathrm{Zn}^{2+}$ is a feasible method to improve the microwave dielectric properties of the $\mathrm{Zn}_{3} \mathrm{~B}_{2} \mathrm{O}_{6}$ ceramic.

Keywords: LTCC; Dielectric properties; DFT; Borate; Solid solutions

\section{Introduction}

Low temperature co-fired ceramics (LTCC) technology has attracted significant research interest recently due to its ability of large scale three-dimensional integration with passive devices. For the inner electrode, the maximum processing temperature of LTCC is the melting point of $\mathrm{Ag}\left(961^{\circ} \mathrm{C}\right) .[1]$ The materials used in the field of microwave communication require both low dielectric constant $\left(\varepsilon_{r}\right)$ and high quality factor $(Q \times f)$.[2] Hence, considering both the electrical characteristics of the material and the processing temperature, the ceramic with low $\varepsilon_{r}$, high $Q \times f$, and low densification temperature has great potential application value in the field of LTCC.[3,4]

Ceramic material based on $\mathrm{Zn}_{3} \mathrm{~B}_{2} \mathrm{O}_{6}$ (ZBO) has recently been studied in the context of batteries and luminescence, but studies on the sintering and microwave dielectric properties of ZBO are less common.[5,6] Wu et al. reported that the ZBO ceramic demonstrated good dielectric properties when sintered at $925^{\circ} \mathrm{C}$, i.e., $\varepsilon_{r}=6.7, Q \times f=58,500 \mathrm{GHz}, \tau_{f}=-58 \mathrm{ppm} /{ }^{\circ} \mathrm{C}$, and relative density $=96 \%$.[7] While the dielectric constant and the sintering temperature of ZBO ceramic are acceptable, the $Q \times f$ value can be improved. Dosler et al. have found that the dielectric properties of the $\mathrm{Mg}_{3} \mathrm{~B}_{2} \mathrm{O}_{6}(\mathrm{MBO})$ ceramic are $\varepsilon_{r}=7, Q \times f=108,000 \mathrm{GHz}, \tau_{f}=-69 \mathrm{ppm} /{ }^{\circ} \mathrm{C}$, and relative density $=97 \%$ sintered at $1350^{\circ} \mathrm{C}$. [8] Considering that the $Q \times f$ value of MBO is larger than that of $\mathrm{ZBO}$, and the densification temperature of $\mathrm{ZBO}$ is smaller than that of $\mathrm{MBO}$, we speculate that the addition of $\mathrm{MBO}$ into $\mathrm{ZBO}$ is a possible way to 
synthesize a composite ceramic with both low densification temperature and high $Q \times f$ value without the increasing the $\varepsilon_{r}$.

The composite ceramic, $(1-\mathrm{x}) \mathrm{ZBO}+\mathrm{xMBO}(x=0.00-0.40)$, was synthesized through the solid-state reaction method. The analysis of microstructure, sintering property, and microwave dielectric properties is included in the discussion. Additionally, the first principle calculation based on the density functional theory (DFT) was used to provide theoretical interpretations.

\section{Experimental procedures}

The raw materials, $\mathrm{ZnO}, \mathrm{MgO}$, and $\mathrm{B}_{2} \mathrm{O}_{3}$, of analytical purity, were from Chron Chemicals Co. Ltd., Chengdu, China. According to the stoichiometric ratio $\left(10 \mathrm{~mol} \%\right.$ excess of $\mathrm{B}_{2} \mathrm{O}_{3}$ for the compensation), these powders were pre-milled for $12 \mathrm{~h}$, pre-sintered at $850^{\circ} \mathrm{C}$ for $4 \mathrm{~h}$ and milled again for $12 \mathrm{~h}$. The medium of milling was distilled water and agate balls. The resulting powders were mixed with the polyvinyl alcohol binder ( $5 \mathrm{wt} \%$ ), pressed into disks ( $6 \mathrm{~mm}$ in thickness and $12 \mathrm{~mm}$ in diameter), and sintered at $900-1000^{\circ} \mathrm{C}$.

The Cambridge Serial Total Energy Package (CASTEP) was used to perform the first principles calculation, and the Vanderbilt ultrasoft pseudopotential was adopted to approximate the interaction of ions and electrons. The exchange-correlation interaction was approximated through the Perdew-Burke-Ernzerhoff function. The linear response method was used to calculate the vibration of atoms. The configuration of the valence electrons was taken as $3 d^{10} 4 s^{2}$ for $\mathrm{Zn}, 2 p^{6} 3 s^{2}$ for $\mathrm{Mg}, 2 s^{2} 2 p^{4}$ for $\mathrm{O}$, and $2 s^{2} 2 p^{1}$ for B. After testing, the parameter of the energy cutoff and the k-point mesh were set as $375 \mathrm{eV}$ and $4 \times 4 \times 3$, respectively. Other parameters include $0.01 \mathrm{eV} / \AA$ (maximum force), $0.02 \mathrm{GPa}$ (maximum stress), $5.0 \times 10^{-6} \mathrm{eV} /$ atom (total energy), $5.0 \times 10^{-6} \mathrm{eV} /$ atom (energy), and 
$0.005 \AA$ (maximum displacement). The optimization of geometry was obtained using the Broyden-Fletcher-Goldfarb-Shanno algorithm. The substituted system was constructed based on a relaxed super cell $(1 \times 2 \times 2,176$ atoms $)$, and the formation energy was obtained using Eq. 1,[9]

$$
\Delta E=E_{D o}-E_{U n D o}-\sum_{i} k_{i} p_{i}
$$

where $E_{D o}$ and $E_{U n D o}$ are the total energy of the doped cell and un-doped cell, $p_{i}$ represents the chemical potentials of the substituted atom, and $k_{i}$ represent the unite coefficient.

X-ray diffraction (XRD: DX-2700, Haoyuan Co.) with $\mathrm{Cu} \mathrm{K}_{\alpha}$ radiation was used to measure the crystal data of samples, which were processed using the Rietveld profile refinement method. The microstructure and the elemental composition were confirmed with the help of scanning electron microscopy (SEM: JEOL, JSM-6490LV) and energy-dispersive X-ray spectroscopy (EDS). Based on the transmission cavity method and the Hakki-Coleman method, the microwave dielectric properties were obtained through the Agilent N5230A Network Analyzer (300MHz-20GHz).[10] The sintering property was investigated by the thermo-mechanical analyzer (TMA: Mettler TMA/SDTA2+) and simultaneous thermal analyzer (TGA\&DSC: Mettler TGA/DSC3+). The temperature coefficient of resonant frequency $\left(\tau_{f}\right)$ was obtained from Eq. 2 using the resonant frequency at $80^{\circ} \mathrm{C}\left(f_{T}\right)$ and $20^{\circ} \mathrm{C}$ $\left(f_{0}\right),[11]$

$$
\tau_{f}=\frac{f_{T}-f_{0}}{f_{0}\left(T-T_{0}\right)} \times 10^{6}
$$

The Archimedes method was used to measure the bulk density.[12] The theoretical $\tau_{f}$, $\varepsilon_{r}$, and $Q$ values were calculated with the mixing rule,[13-15]

$$
\begin{gathered}
\tau_{f}=v_{a} \times \tau_{f a}+v_{b} \times \tau_{f b} \\
\ln \varepsilon_{r}=v_{a} \ln \varepsilon_{r a}+v_{b} \ln \varepsilon_{r b} \\
\frac{1}{Q}=\frac{v_{a}}{Q_{a}}+\frac{v_{b}}{Q_{b}}
\end{gathered}
$$


where $v_{a(b)}$ is the volume fraction of phase a(b); $\tau_{f a(b)}, \varepsilon_{r a(b)}$ and $Q_{a(b)}$ are the dielectric properties of phase $\mathrm{a}(\mathrm{b})$. The activation energies $\left(\mathrm{E}_{\mathrm{a}}\right)$ were calculated using the Arrhenius expression, [16]

$$
\ln k=\frac{-E_{a}}{R}\left(\frac{1}{T}\right)+\ln z
$$

where $R(8.3145 \mathrm{~J} / \mathrm{K} / \mathrm{mol})$ is the gas constant, $k$ is the heating rate $(5,10$, and $15 \mathrm{~K} / \mathrm{min}), T$ is the temperature (Kelvin), and $z$ is Arrhenius constant.

\section{Results and discussion}
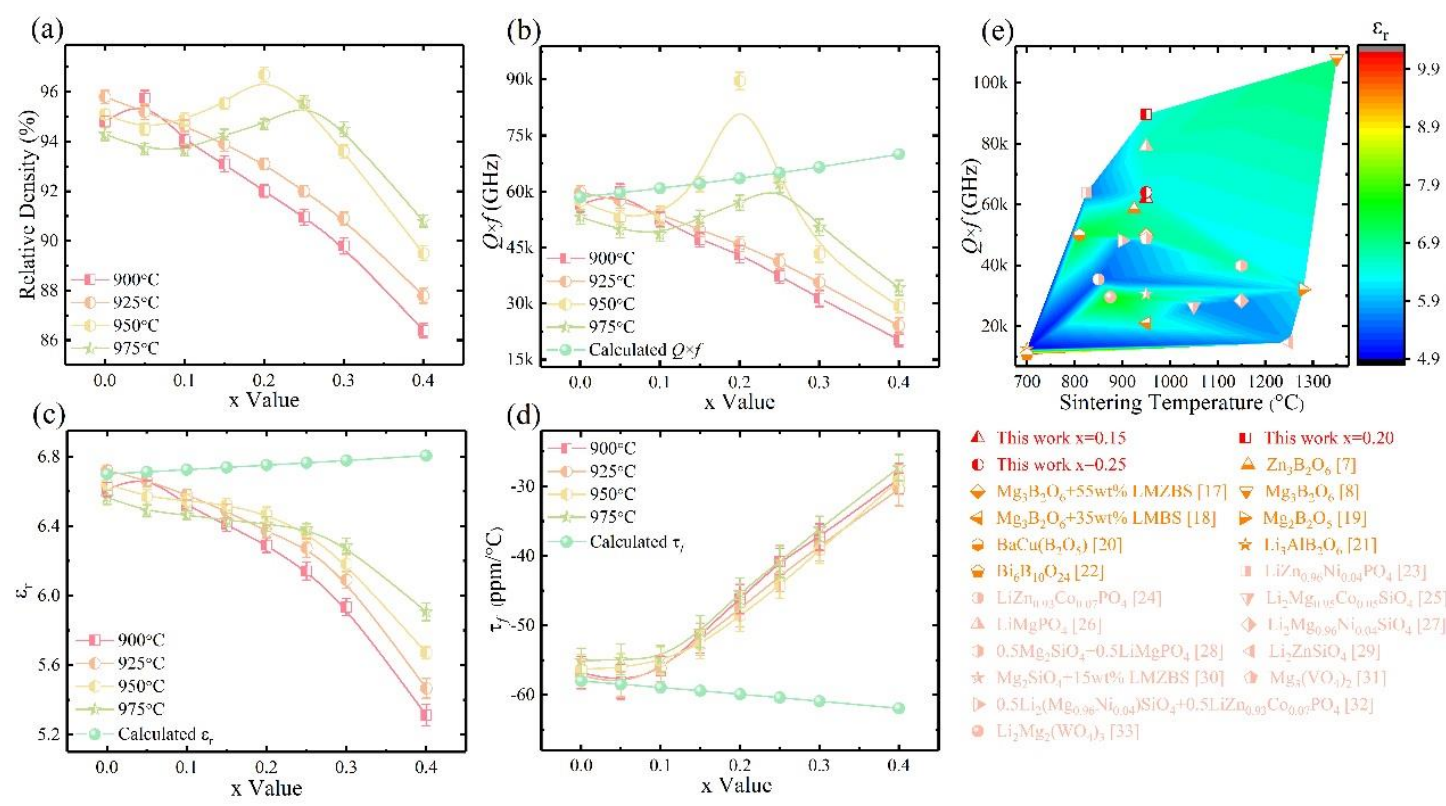

Fig. 1 Relative density (a), $Q \times f(\mathrm{~b}), \varepsilon_{r}(\mathrm{c})$, and $\tau_{f}(\mathrm{~d})$ values of the $(1-\mathrm{x}) \mathrm{ZBO}+\mathrm{xMBO}(x=0.00-0.40)$

ceramics sintered at different temperature; summary of sintering and dielectric properties of various ceramics (e)

Fig. 1(a-d) present the dielectric properties of the $(1-\mathrm{x}) \mathrm{ZBO}+\mathrm{xMBO}$ ceramics sintered at different temperatures. The relative density value shows a trend of (i) first increasing and then decreasing for samples sintered at $900^{\circ} \mathrm{C}$, (ii) monotonous decreasing for samples sintered at $925^{\circ} \mathrm{C}$, and (iii) wavy for 
the one sintered at 950 and $975^{\circ} \mathrm{C}$. The peak density value was $96.7 \%$ for the sample with $\mathrm{x}=0.20$ sintered at $950^{\circ} \mathrm{C}$. The variation trend that the $Q \times f$ value presents is in accordance with that of the relative density, and it peaked at $x=0.20,89,600 \mathrm{GHz}$ at $15.2 \mathrm{GHz}$, which can be attributed to the strong interdependence between these two parameters. As $\mathrm{x}$ increases, the $\varepsilon_{r}$ value shows a monotonously decreasing trend, except for the sample sintered at $900^{\circ} \mathrm{C}$, which shows a parabolic trend, and $\varepsilon_{r}=6.47$ as $x=0.20$ sintered at $950^{\circ} \mathrm{C}$. The relative density variation could be one reason for the variation of the $\varepsilon_{r}$ value since the sample with a high level of densification shows a relatively high $\varepsilon_{r}$ value and samples with low density show low $\varepsilon_{r}$ values. The $\tau_{f}$ value shows an overall increasing trend with $\tau_{f}=-48.6 \mathrm{ppm} /{ }^{\circ} \mathrm{C}$ for $x=0.20$ sintered at $950^{\circ} \mathrm{C}$. Therefore, a moderate addition of $\mathrm{Mg}^{2+}$ improved the densification level, $Q \times f$ value, and thermal stability while decreasing the $\varepsilon_{r}$ value of the ZBO ceramic. As shown in Fig. 1(e), the composite ceramics synthesized in this experiment provided both excellent dielectric and sintering properties when compared with other ceramics.[7, 8, 17-33] 
(a)

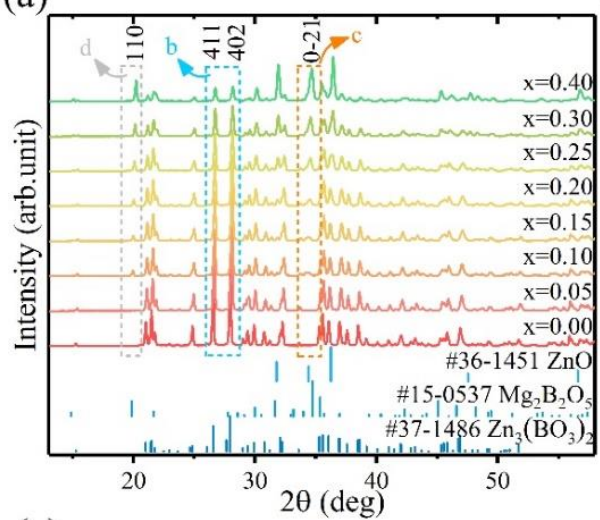

(e)

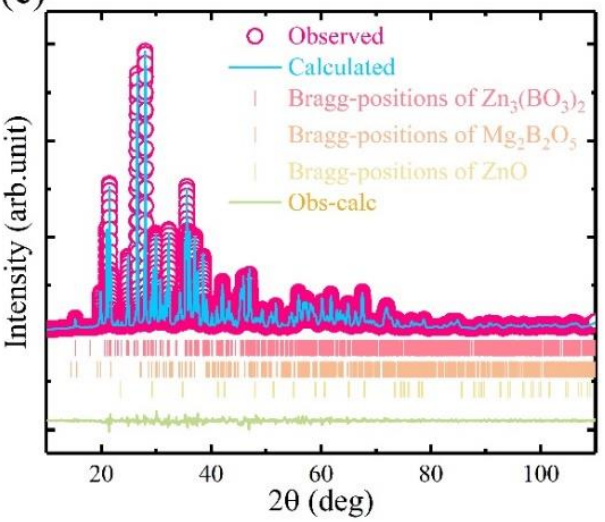

(b)

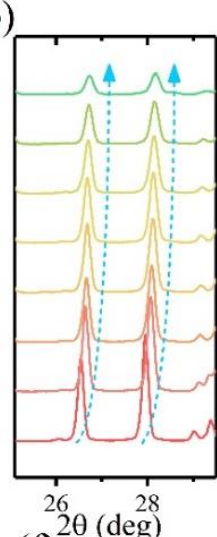

(c)

(f)

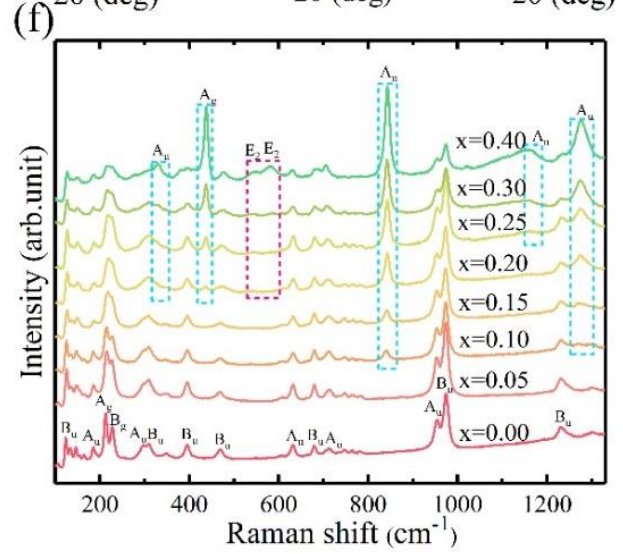

Fig. 2 XRD patterns of the $(1-\mathrm{x}) \mathrm{ZBO}+\mathrm{xMBO}(x=0.00-0.40)$ ceramics sintered at $950^{\circ} \mathrm{C}(\mathrm{a}-\mathrm{d})$;

experimental and calculated profiles of the $0.8 \mathrm{ZBO}+0.2 \mathrm{MBO}$ ceramic sintered at $950^{\circ} \mathrm{C}(\mathrm{e})$;

Raman spectroscopy of the (1-x)ZBO+xMBO $(x=0.00-0.40)$ ceramics sintered at $950^{\circ} \mathrm{C}$

Fig. 2(a-d) presents the XRD patterns of all the samples processed at the same temperature $\left(950^{\circ} \mathrm{C}\right)$. A single $\mathrm{ZBO}$ phase (JCPDS\#37-1486) was formed for the samples with $\mathrm{x}=0.00$ and 0.05 and increasing the $\mathrm{Mg}^{2+}$ content resulted in the emergence of the $\mathrm{Mg}_{2} \mathrm{~B}_{2} \mathrm{O}_{5}$ phase (JCPDS\#15-0537) and the ZnO phase (JCPDS\#36-1451). The peak intensity of ZBO was seen to decrease, and that of $\mathrm{Mg}_{2} \mathrm{~B}_{2} \mathrm{O}_{5}$ and $\mathrm{ZnO}$ increased as the $\mathrm{x}$ value increased. The (411) and (402) peaks of the ZBO ceramic and the (110) and (0-21) peaks of the $\mathrm{Mg}_{2} \mathrm{~B}_{2} \mathrm{O}_{5}$ ceramic shifted to a higher angle, indicating that the cell volume of both the $\mathrm{ZBO}$ ceramic and the $\mathrm{Mg}_{2} \mathrm{~B}_{2} \mathrm{O}_{5}$ ceramic decreased on increasing $\mathrm{Mg}^{2+}$-ions. Considering that the ionic radius of $\mathrm{Zn}^{2+}(0.60 \AA)$ was larger than that of $\mathrm{Mg}^{2+}$ 
$(0.57 \AA)$ and that the $\mathrm{Mg}^{2+}$ concentration increased with increase in the $\mathrm{x}$ value, the ion substitution level of $\mathrm{Mg}^{2+}$ to $\mathrm{Zn}^{2+}$ ( $\mathrm{ZBO}$ ceramic) could have strengthened, and that of $\mathrm{Zn}^{2+}$ to $\mathrm{Mg}^{2+}\left(\mathrm{Mg}_{2} \mathrm{~B}_{2} \mathrm{O}_{5}\right.$ ceramic) could have weakened, thus, explaining the variation in volume.[34] The detailed lattice parameters obtained from refinement are provided in Fig. 2e, Table I, and Fig. 3. The theoretical, calculated, and measured values match well; the Fullprof parameters are satisfactory. For the ZBO ceramics, parameters a, $\mathrm{c}$, and the volume tend to decrease; $\mathrm{b}$ and $\beta$ increase; and $\alpha$ and $\gamma$ remain unchanged. For the $\mathrm{Mg}_{2} \mathrm{~B}_{2} \mathrm{O}_{5}$ ceramic, parameters a, b, c, and the volume tend to decrease, while $\alpha, \beta$, and $\gamma$ increase. The variation of lattice parameters is consistent with the observations from the XRD data. It should be noted that both the formed component and component fraction is different from the designed one. The designed fraction value of the ZBO ceramic is smaller than that measured for $x \leq 0.20$, and the designed value exceeds the measured value when $\mathrm{x}>0.20$. The mutual ion substitution, i.e., $\mathrm{Mg}^{2+}$ to $\mathrm{Zn}^{2+}$ for $\mathrm{ZBO}$ ceramic and $\mathrm{Zn}^{2+}$ to $\mathrm{Mg}^{2+}$ for $\mathrm{Mg}_{2} \mathrm{~B}_{2} \mathrm{O}_{5}$ ceramic, and the formation of $\mathrm{ZnO}$ ceramic can explain this discrepancy. The fraction of $\mathrm{Mg}_{2} \mathrm{~B}_{2} \mathrm{O}_{5}$ and $\mathrm{ZnO}$ ceramic increased with the addition of $\mathrm{Mg}^{2+}$ when $\mathrm{x} \geq 0.10$. Since the densification temperature of $\mathrm{ZBO}$ is $925^{\circ} \mathrm{C}$, the increasing density for the sample with $\mathrm{x}=0.05$ sintered at $900^{\circ} \mathrm{C}$ should be attributed to the decreasing densification temperature due to lattice distortion, and the decreasing density value for the same sample sintered at $925-975^{\circ} \mathrm{C}$ can be ascribed to the over-sintering. The decreasing density of samples sintered at 900 , and $925^{\circ} \mathrm{C}$ is a result of the formation of $\mathrm{Mg}_{2} \mathrm{~B}_{2} \mathrm{O}_{5}$, which has a densification temperature of about $1280^{\circ} \mathrm{C} .[19]$ The increment of density for samples sintered at 950 and $975^{\circ} \mathrm{C}$ can be attributed to the reduction in the extent of over-sintering, and any subsequent decrease is the same as that of the sample sintered at a lower temperature. Since the $\mathrm{Mg}_{2} \mathrm{~B}_{2} \mathrm{O}_{5}$ ceramic has a relatively lower $\varepsilon_{r}(6.2)$ and higher $\tau_{f}\left(-18 \mathrm{ppm} /{ }^{\circ} \mathrm{C}\right)$ compared to that of the ZBO ceramic, the formation of a heterophase can explain 
the difference between the measured and calculated $\varepsilon_{r} / \tau_{f}$ value except for the density level variation.[19] However, the $Q \times f$ value of the composite ceramic with $\mathrm{x}=0.20$ sintered at $950^{\circ} \mathrm{C}$ is larger than that of both $\mathrm{ZBO}$ and $\mathrm{Mg}_{2} \mathrm{~B}_{2} \mathrm{O}_{5}(32,100 \mathrm{GHz}$ at $12.6 \mathrm{GHz})$ ceramic.[19] These phenomena can be explained by the modification of the crystal structure led by mutual substitution, the formation of a solid solution with three phases, and the improved density level. Furthermore, the existence of the $\mathrm{ZnO}$ phase also has an impact on the sintering and dielectric properties of the composite ceramics.

The Raman spectra of all samples were obtained to further study phase formation, as shown in Fig. 2(f). According to the Bilbao Crystallographic Server and CASTEP, the vibration modes for ZBO, $\mathrm{Mg}_{2} \mathrm{~B}_{2} \mathrm{O}_{5}$, and $\mathrm{ZnO}$ ceramics are as follows,

$$
\begin{gathered}
\Gamma_{\text {optic }}=33 A_{\mathrm{g}}(R)+32 A_{u}(I R)+33 B_{g}(R)+31 B_{u}(I R) \\
\Gamma_{\text {Optic }}=27 A_{\mathrm{g}}(R)+24 A_{u}(I R) \\
\Gamma_{\text {Optic }}=A_{1}(I R \& R)+2 B_{1}(R)+2 E_{2}(R)+E_{1}(I R \& R)
\end{gathered}
$$

where R corresponds to the Raman mode, and IR corresponds to the Infrared mode. Considering the testing error due to the peak overlap, sample shape, and temperature of the test environment, the peaks obtained from the experiment and calculation fitted well. For the sample with pure ZBO phase $(\mathrm{x}=0.00)$, the vibration modes at the frequency lower than $503 \mathrm{~cm}^{-1}$ were the external modes (rotational and translational modes of $\mathrm{ZnO}_{4}$ ), and the other half were the internal modes (bending and stretching vibration modes of $\mathrm{BO}_{3}$ ). The increasing value of $\mathrm{x}$ is seen to result in the weakening of peaks belonging to ZBO and the enhancement of other peaks; the formation of $\mathrm{Mg}_{2} \mathrm{~B}_{2} \mathrm{O}_{5}$ (blue dashed box) and $\mathrm{ZnO}$ (pink dashed box) phases could be the reason for such a variation.[35] The dividing point of external and internal modes for $\mathrm{Mg}_{2} \mathrm{~B}_{2} \mathrm{O}_{5}$ ceramic is $740 \mathrm{~cm}^{-1}$. The external modes involve the rotational and translational modes of $\mathrm{MgO}_{6}$, and the internal modes are the same as the $\mathrm{ZBO}$ ceramic. 
Therefore, the discussion regarding the phase composition obtained from XRD can be confirmed by the Raman spectra.

Table I. Refinement and lattice parameters of the $(1-\mathrm{x}) \mathrm{ZBO}+\mathrm{xMBO}(x=0.00-0.40)$ ceramics by the Rietveld profile refinement method

\begin{tabular}{cccccccccc}
\hline Parameters & $x=0.00$ & $x=0.05$ & $x=0.10$ & $x=0.15$ & $x=0.20$ & $x=0.25$ & $x=0.30$ & $x=0.40$ \\
\hline$R_{p}(\%)$ & 5.14 & 6.02 & 6.24 & 6.35 & 6.41 & 6.37 & 5.56 & 5.91 \\
$R_{\text {wp }}(\%)$ & 5.92 & 6.12 & 6.89 & 7.16 & 7.29 & 7.48 & 7.22 & 7.31 \\
$R_{\exp }(\%)$ & 5.01 & 5.21 & 5.85 & 6.17 & 6.20 & 6.28 & 5.36 & 5.44 \\
$\chi^{2}$ & 1.40 & 1.38 & 1.39 & 1.35 & 1.38 & 1.42 & 1.81 & 1.81 \\
\hline
\end{tabular}
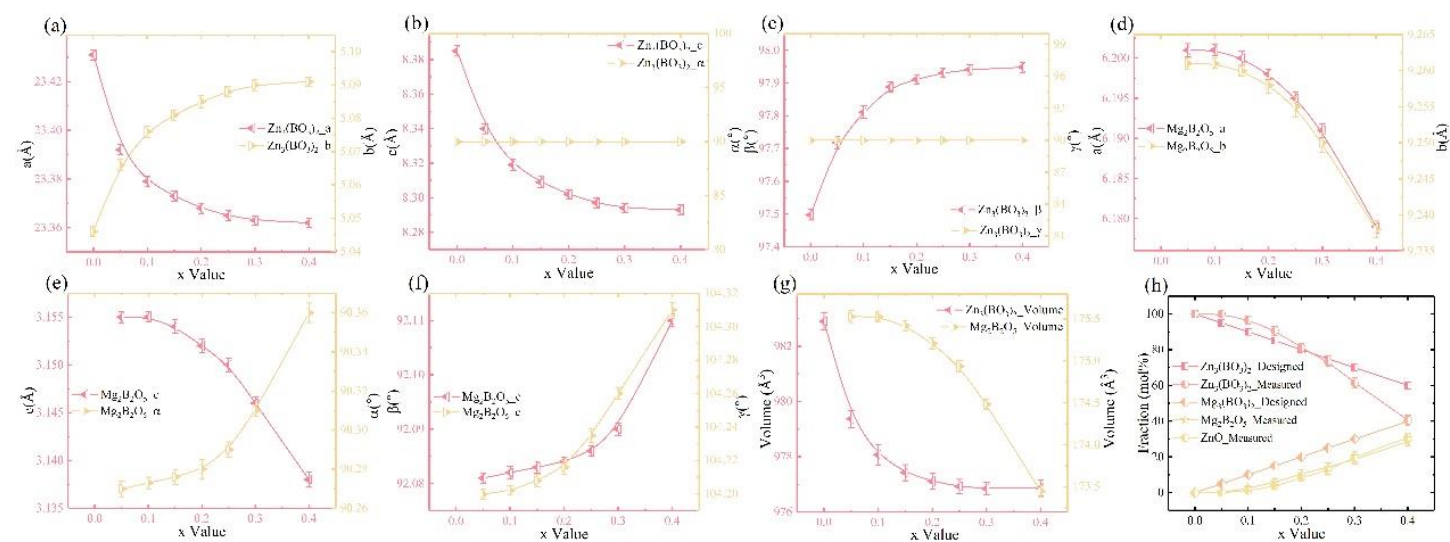

Fig. 3 Lattice parameters of $\mathrm{ZBO}$ and $\mathrm{Mg}_{2} \mathrm{~B}_{2} \mathrm{O}_{5}$ ceramics sintered at different temperature 


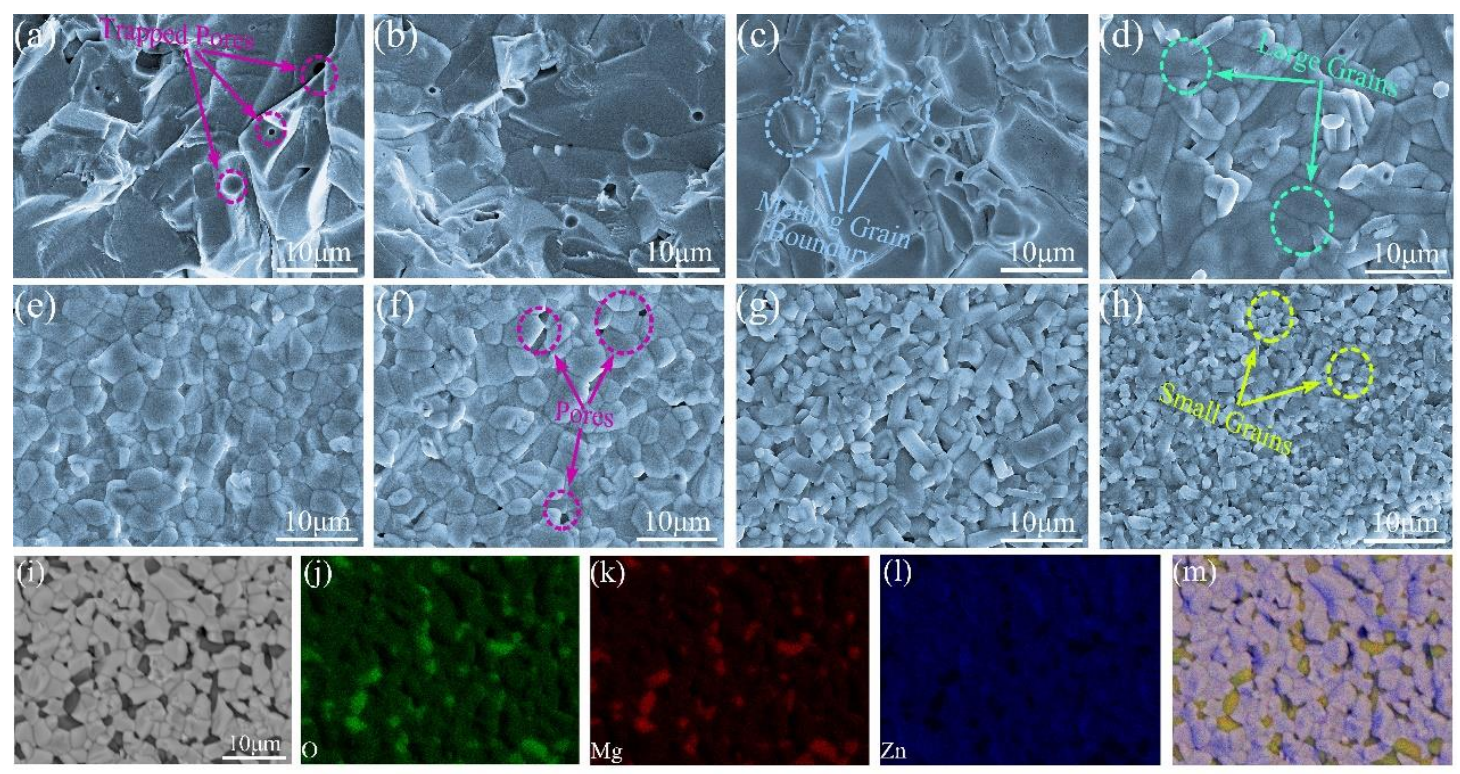

Fig. 4 SEM micrographs of the $(1-\mathrm{x}) \mathrm{ZBO}+\mathrm{xMBO}(x=0.00-0.40)$ ceramics sintered at $950^{\circ} \mathrm{C}(\mathrm{a}-\mathrm{h})$;

EDS mapping images of the $0.8 \mathrm{ZBO}+0.2 \mathrm{MBO}$ ceramic sintered at $950^{\circ} \mathrm{C}(\mathrm{i}-\mathrm{m})$
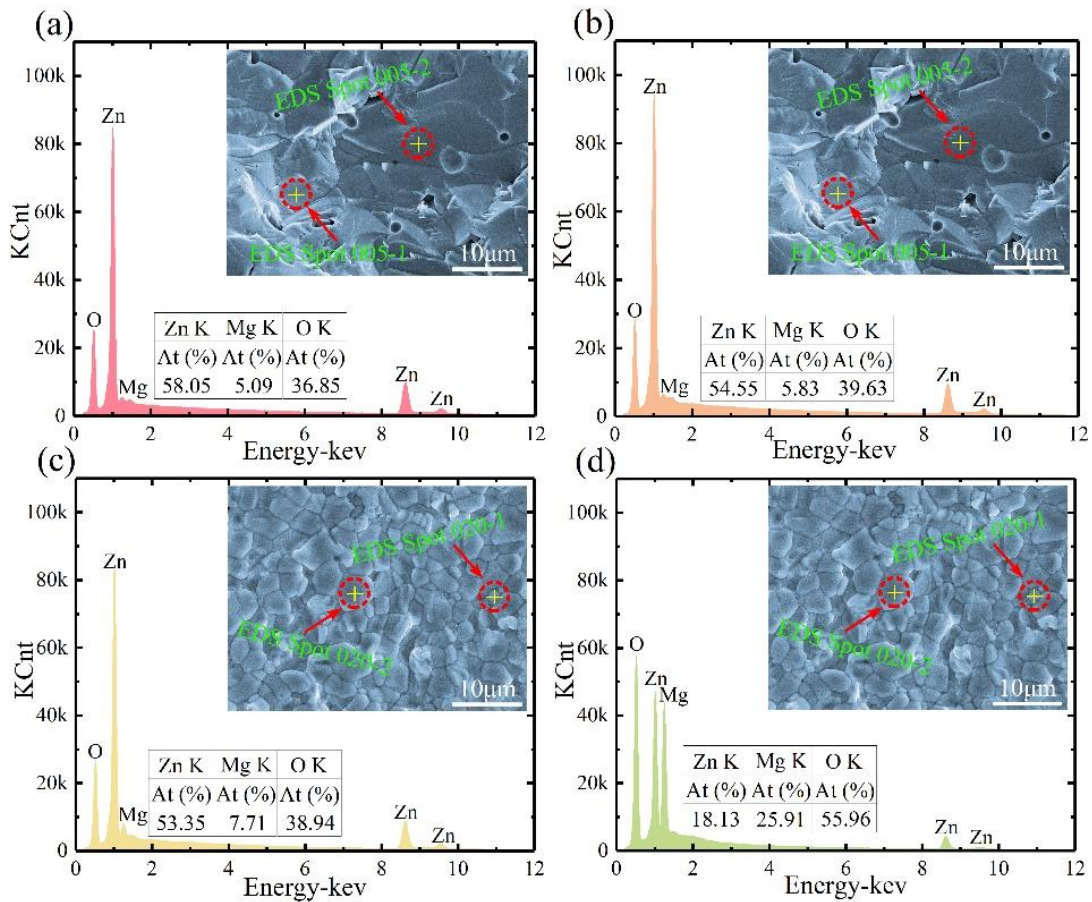

Fig. 5 EDS result of the $(1-\mathrm{x}) \mathrm{ZBO}+\mathrm{xMBO}(x=0.00-0.40)$ ceramics as $x=0.05(\mathrm{a}, \mathrm{b})$ and $x=0.20(\mathrm{c}, \mathrm{d})$ 
The microstructure of the samples sintered at $950^{\circ} \mathrm{C}$ is shown in the SEM images in Fig. 4. The trapped pores (pink circles) and melting grain boundaries (blue circles) are observed in Fig. 4(a-c), and abnormal grain growth is observed in Fig. 4(d) which is scattered with large grains (green circles). A compact microstructure is obtained in the sample with $\mathrm{x}=0.20$, and any further addition of $\mathrm{Mg}^{2+}$ leads to the reduction of grain size (yellow circles) and the emergence of pores (pink circles) at the same sintering temperature. The behavior observed from the SEM images fits well with the relative density trends observed. Fig. 4(i-m) show the EDS mapping of the sample with $\mathrm{x}=0.20$, where the distribution of oxygen, zinc, and magnesium are shown to be uneven. The O-rich grains are also Mg-rich, and the other grains which are Zn-rich relatively lack O. The relationship between the zinc and magnesium content is in accordance with the design one generally. EDS was conducted to confirm the composition of the composite materials $(x=0.05, x=0.20)$ sintered at $950^{\circ} \mathrm{C}$, as shown in Fig. 5 . All elements were detected except for boron (too light). The atomic ratio of $\mathrm{Zn}: \mathrm{Mg}$ : $\mathrm{O}$ is 58.05: 5.09: 36.85 for spot 005-1, 54.55: 5.83: 39.63 for spot 005-2, 53.35: 7.71: 38.94 for spot 020-1, and 18.13: 25.91: 55.96 for spot $020-2$. The EDS result for $\mathrm{x}=0.05$ sample is consistent with the designed value, demonstrating that no second phase was generated and that the ZBO phase was distributed uniformly. However, this two mole ratio values of $\mathrm{Zn}: \mathrm{Mg}$ : $\mathrm{O}$ for the $\mathrm{x}=0.20$ sample was different, and the content of various elements was different from different grains. The grain at spot 020-1 tested $\mathrm{Zn}$-rich and the grain at spot 020-2 was O\&Mg-rich, which is consistent with the result from EDS mapping. Therefore, the EDS results confirmed the observations made from XRD regarding the phase formation.

In order to analyze the sintering property of the $(1-\mathrm{x}) \mathrm{ZBO}+\mathrm{xMBO}(x=0.00-0.40)$ ceramics, TG, DSC and TMA were conducted (Fig. 6(a-c)). The temperature increase from $100^{\circ} \mathrm{C}$ to $300^{\circ} \mathrm{C}$ led to a weight loss of about $11 \%$. The first stage of weight loss can be ascribed to the removal of hydration 
water, and the decomposition of $\mathrm{H}_{3} \mathrm{BO}_{3}$ (formed from the reaction of $\mathrm{B}_{2} \mathrm{O}_{3}$ and distilled water). The further decomposition of $\mathrm{H}_{3} \mathrm{BO}_{3}$ could be responsible for the second stage of gradual weight loss (slight) from $300^{\circ} \mathrm{C}$ to $600^{\circ} \mathrm{C}$. After that, the dynamic atom equilibrium was achieved, and the negligible weight loss was observed for temperatures higher than $600^{\circ} \mathrm{C}$. The DSC curves show an endothermic peak at around $200^{\circ} \mathrm{C}$, corresponding to the first stage of weight loss. The exothermic peak near $610^{\circ} \mathrm{C}$ can be ascribed to the crystallization of the ZBO ceramic and the further decomposition of $\mathrm{H}_{3} \mathrm{BO}_{3}$. The exothermic peak at a relatively higher temperature (blue dotted box) could be attributed to the formation of $\mathrm{Mg}_{2} \mathrm{~B}_{2} \mathrm{O}_{5}$, which corresponds to further weight loss near $680^{\circ} \mathrm{C}$ (blue dotted box). It should be noted that the increasing $\mathrm{Mg}^{2+}$ content shifts the weight loss and endothermic peak near $200^{\circ} \mathrm{C}$ to a lower temperature, and also shifts the exothermic peak for the formation of ZBO ceramic to a relatively higher temperature. The TMA patterns show that the onset point of shrinkage move to a higher temperature, which matches the observations from the TG and DSC. Hence, the addition of $\mathrm{Mg}^{2+}$ led to a slightly higher temperature window of densification of the ZBO ceramic, and the heterophase was formed with a relatively high $x$ value. The activation energy was calculated at the temperature where $3 \%, 6 \%$, and $9 \%$ shrinkage was observed to further investigate the sintering properties. The $l n k$ versus $1 / T$ plots are shown in Fig. 6(d-k).[36] Calculations (Fig. 6(1)) show that the $E_{a}$ value tends to decrease and then increase. The initial decrease of $E_{a}$ demonstrates that the lattice distortion (led by $5 \% \mathrm{Mg}^{2+}$ substitution) could lower the densification temperature of ZBO ceramic as discussed in context to the relative density. The followed increase in $E_{a}$ verifies that the heterophase could indeed increase the densification temperature of the composite ceramic at $x \geq 0.10$. Specifically, the sample with the addition of $5 \% \mathrm{Mg}^{2+}$ had the lowest $E_{a}(407 \pm 183 \mathrm{~kJ} / \mathrm{mol})$, and the $E_{a}$ value for $\mathrm{x}=0.20$ sample was $598 \pm 221 \mathrm{~kJ} / \mathrm{mol}$. 

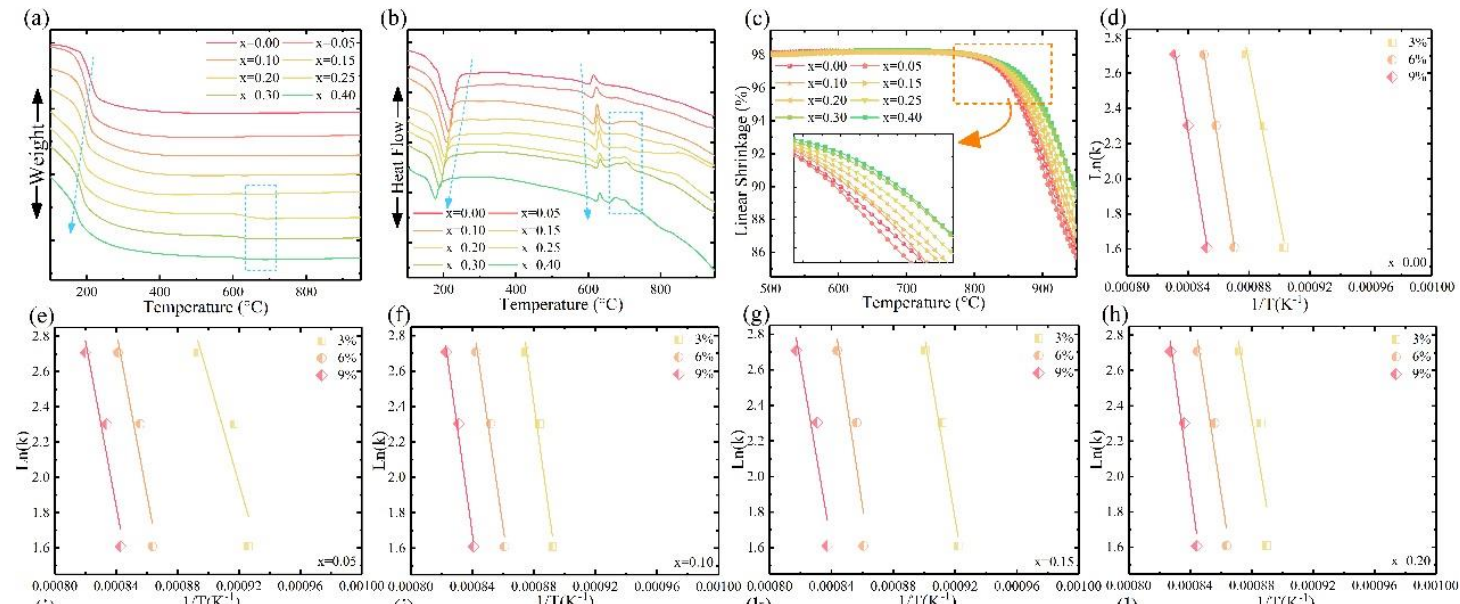

(h) $\quad 1 / 7\left(\mathrm{~K}^{-1}\right)$
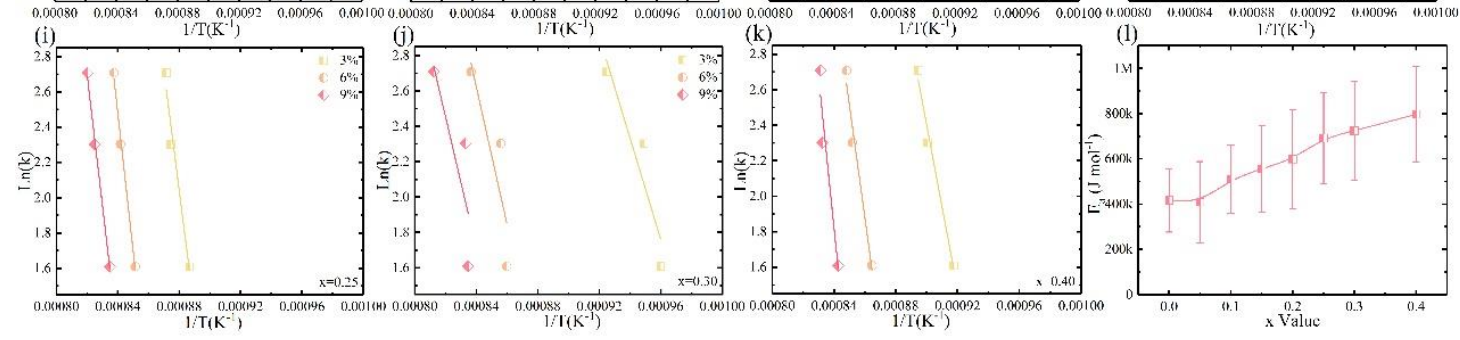

Fig. 6 TG, DSC, TMA and sintering rate plotted against the inverse of temperature of the $(1-\mathrm{x}) \mathrm{ZBO}+\mathrm{xMBO}(x=0.00-0.40)$ ceramics

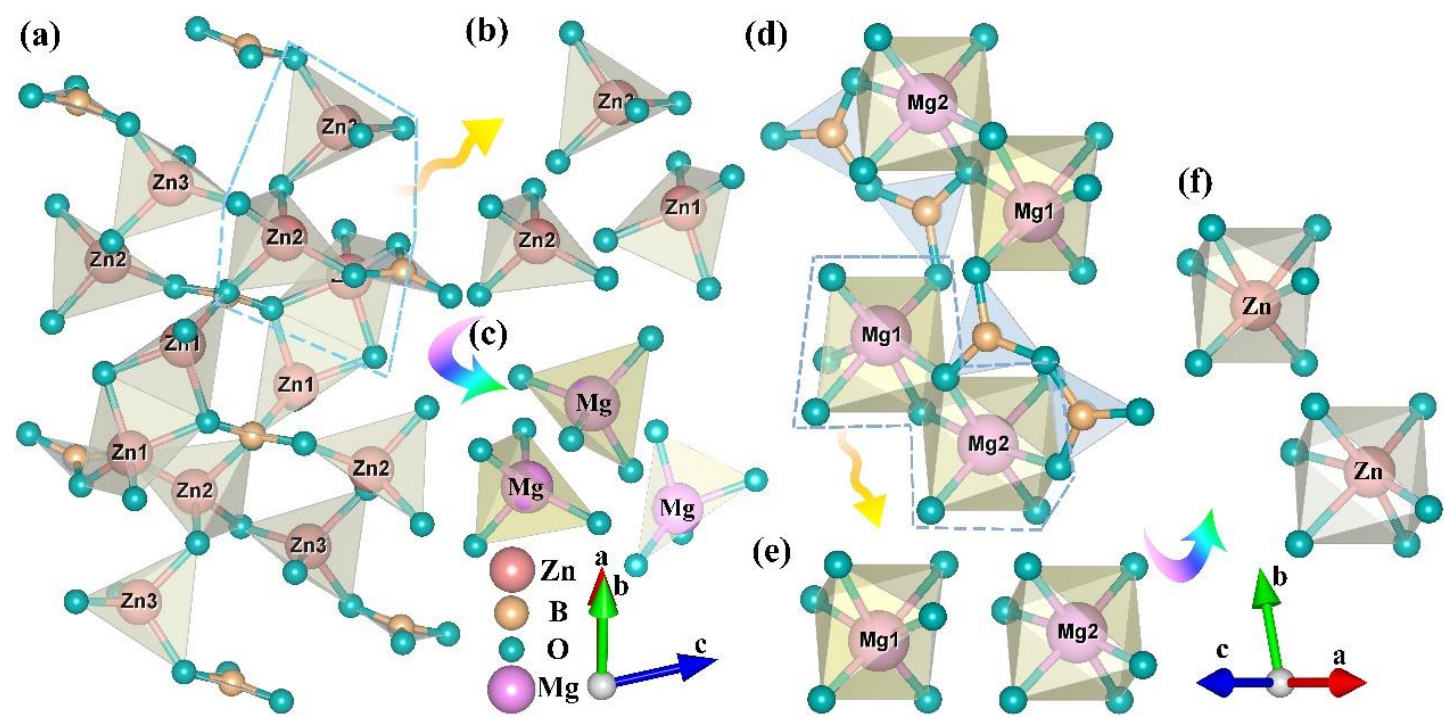

Fig. 7 Crystal structure of $\mathrm{ZBO}$ (a); schematic diagram of $\mathrm{ZnO}_{4}$ tetrahedron before and after $\mathrm{Mg}^{2+}$ substitution (b-c); crystal structure of $\mathrm{Mg}_{2} \mathrm{~B}_{2} \mathrm{O}_{5}(\mathrm{~d})$; schematic diagram of $\mathrm{MgO}_{6}$ octahedron before and after $\mathrm{Zn}^{2+}$ substitution (e-f) 
DFT calculations were performed to explain the variation mechanism of sintering and dielectric properties. The crystal structure and schematic diagram of the ion substitution can be observed in Fig. 7. The lattice parameters are $I 2 / c$ (No.15), $a=23.406 \AA, b=5.048 \AA, c=8.381 \AA, \alpha=90^{\circ}, \beta=97.53^{\circ}, \gamma=90^{\circ}$ for

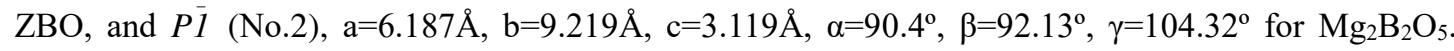
There are three types of $\mathrm{ZnO}_{4}$ tetrahedrons in $\mathrm{ZBO}$ and two types of $\mathrm{MgO}_{6}$ octahedrons in $\mathrm{Mg}_{2} \mathrm{~B}_{2} \mathrm{O}_{5}$, as illustrated in Fig. 7(b, e). Each zinc/magnesium atom has been substituted by magnesium/zinc atom one by one, and the microstructural properties (electron density, bond length and population) of the atomic groups have been modified after optimization of geometry (Fig. 7(c, f), Fig. 8, Table II). The modification of the position of the ion happened for each $\mathrm{ZnO}_{4}$ tetrahedron and $\mathrm{MgO}_{6}$ octahedron. According to the value shown in Table II (Length/Population-B/A means the bond length/population before/after ion substitution, Length- $\mathrm{E}$ means the bond length as $\mathrm{x}=0.2$ sintered at $950^{\circ} \mathrm{C}$ ), all the bond length values increased for both the $\mathrm{ZnO}_{4}$ tetrahedron and the $\mathrm{MgO}_{6}$ octahedron after substitution. The variation tendency of bond population is negative for $\mathrm{ZnO}_{4}$ tetrahedron and positive for $\mathrm{MgO}_{6}$ octahedron. A higher value of bond population corresponds to a higher covalency for the cation and oxygen-ion bond. The variation of bond length and population should be ascribed to the diversity of extranuclear electron pairing status for $\mathrm{Zn}^{2+}\left(3 d^{10}\right)$ and $\mathrm{Mg}^{2+}\left(2 p^{6}\right)$, and the difference of ionic polarizability and ionic radius between $\mathrm{Zn}^{2+}\left(2.04 \AA^{3}\right)$ and $\mathrm{Mg}^{2+}\left(1.32 \AA^{3}\right)$ also should be responsible for such variation.[34, 37] It should be noted that the variation of covalency can have an influence on the improvement of the sintering properties, as discussed in the thermal analysis section. The bond lengths (Length-E) obtained from the experiments, the variation trend of it is identical with that of calculation, indicating that all the positions of the zinc and magnesium atoms have participated in the mutual 
replacement process, verifying the observations from XRD. The nature of the bonds can be further obtained from the electron density distribution; the (001) plane around the $\mathrm{Zn}^{2+} / \mathrm{Mg}^{2+}$ is presented in Fig. 8. Compared to the doped and un-doped plane with the $\mathrm{ZnO}_{4}$ tetrahedron, the electron density has decreased, and the electron interaction between cation and oxygen shows a weakening trend. However, all the variations for the plane containing the $\mathrm{MgO}_{6}$ octahedron are opposite to that of the $\mathrm{ZnO}_{4}$ tetrahedron. The electron distribution symmetry in both $\mathrm{ZnO}_{4}$ tetrahedron and $\mathrm{MgO}_{6}$ octahedron was broken. This phenomenon can be attributed to the larger polarizability of $\mathrm{Zn}^{2+}$ compared to that of $\mathrm{Mg}^{2+}$, and the variation of the bond parameters reflects the changes in the electron distribution. The modification of the electron distribution and bond properties led by mutual substitution are an intrinsic factor for the improvement of the $Q \times f$ value of the composite ceramic.[38]

Table II. Bond length and bond population of $\mathrm{ZnO}_{4}$ tetrahedron with $\mathrm{Mg}^{2+}$ substitution and $\mathrm{MgO}_{6}$ octahedron with $\mathrm{Zn}^{2+}$-ion substitution; bond length of $\mathrm{ZnO}_{4}$ tetrahedron and $\mathrm{MgO}_{6}$ octahedron when $\mathrm{x}=0.2$ sintered at $950^{\circ} \mathrm{C}$

\begin{tabular}{ccccccc}
\hline Cation & Anion & Length-B $(\AA)$ & Length-A $(\AA)$ & Length-E $(\AA)$ & Population-B & Population-A \\
\hline \multirow{2}{*}{$\mathrm{Zn} 1$} & $\mathrm{O} 14$ & 1.91396 & 1.97717 & 1.93546 & 0.45 & -1.38 \\
& $\mathrm{O} 15$ & 1.93280 & 2.01284 & 1.96620 & 0.37 & -1.03 \\
& $\mathrm{O} 7$ & 1.96685 & 2.06893 & 1.99855 & 0.37 & -0.79 \\
& $\mathrm{O} 1$ & 2.06862 & 2.07404 & 2.07058 & 0.28 & -0.89 \\
& $\mathrm{O} 21$ & 1.91351 & 1.98619 & 1.92115 & 0.44 & -1.24 \\
$\mathrm{Zn} 2$ & $\mathrm{O} 4$ & 1.95872 & 1.99755 & 1.96074 & 0.41 & -1.17 \\
& $\mathrm{O} 2$ & 1.98725 & 2.01241 & 1.99206 & 0.36 & -1.07 \\
& $\mathrm{O} 24$ & 1.99945 & 2.04499 & 2.01423 & 0.35 & -0.93 \\
& $\mathrm{O} 16$ & 1.93785 & 1.98771 & 1.95009 & 0.46 & -1.23 \\
$\mathrm{Zn} 3$ & $\mathrm{O} 17$ & 1.95936 & 1.98718 & 1.96087 & 0.39 & -1.27 \\
& $\mathrm{O} 18$ & 1.97306 & 2.03677 & 1.99233 & 0.32 & -1.01 \\
\hline
\end{tabular}




\begin{tabular}{ccccccc}
\hline & O23 & 1.98923 & 2.01080 & 1.99544 & 0.36 & -1.09 \\
& O2 & 1.97648 & 2.00101 & 1.98221 & -2.18 & 0.58 \\
& O8 & 2.06725 & 2.07712 & 2.07032 & -0.95 & 0.22 \\
$\mathrm{Mg} 1$ & O9 & 2.16879 & 2.20867 & 2.18019 & -0.65 & 0.04 \\
& O10 & 2.21794 & 2.26116 & 2.23021 & -0.58 & 0.30 \\
& O3 & 2.61087 & 2.68428 & 2.64098 & -0.65 & -0.48 \\
& O4 & 2.89551 & 2.94423 & 2.90469 & -0.37 & 0.50 \\
& O11 & 2.04859 & 2.04929 & 2.04881 & -0.87 & 0.26 \\
& O1 & 2.06306 & 2.09609 & 2.07585 & -1.45 & 0.44 \\
& O7 & 2.09595 & 2.11315 & 2.10093 & -1.14 & 0.43 \\
& O6 & 2.14581 & 2.24873 & 2.18749 & -0.60 & 0.07 \\
& O5 & 2.96057 & 2.98658 & 2.97014 & -0.31 & 0.46 \\
& O12 & 2.98457 & 2.99154 & 2.98922 & -0.34 & 0.47 \\
\hline
\end{tabular}

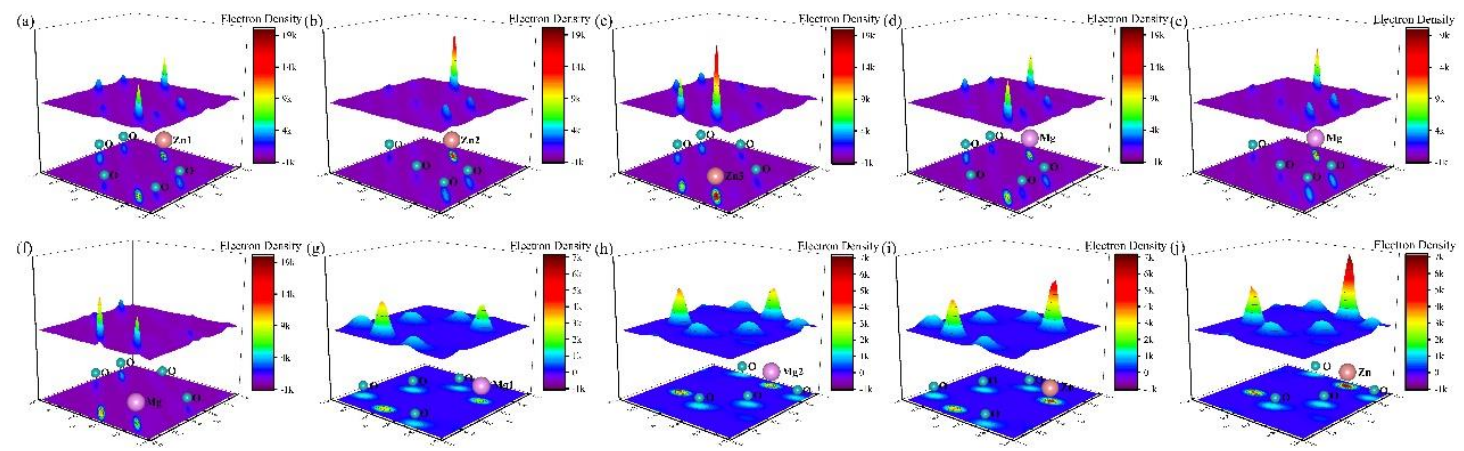

Fig. 8 Electron density map of the plane with three kinds of $\mathrm{Zn}^{2+}$ before (a-c) and after (d-f) $\mathrm{Mg}^{2+}$ substitution, and the plane with two kinds of $\mathrm{Mg}^{2+}$ before (g-h) and after (i-j) $\mathrm{Zn}^{2+}$ substitution In order to further investigate the phase formation property of the $(1-\mathrm{x}) \mathrm{ZBO}+\mathrm{xMBO}(x=0.00-0.40)$ composite ceramics, the formation and total energy of the system have been calculated (chemical potentials are $-973.5126 \mathrm{eV}$ for $\mathrm{Mg},-1710.5005 \mathrm{eV}$ for $\mathrm{Zn},-7912.8141 \mathrm{eV}$ for $\mathrm{ZBO},-5712.6593 \mathrm{eV}$ for $\mathrm{Mg}_{3} \mathrm{~B}_{2} \mathrm{O}_{6},-4298.7629 \mathrm{eV}$ for $\mathrm{Mg}_{2} \mathrm{~B}_{2} \mathrm{O}_{5}$, and $-2147.1981 \mathrm{eV}$ for $\mathrm{ZnO}$ ), and the result is presented in 
Fig. 9. The formation energy of all doped crystals for the ZBO ceramic is negative, and for the $\mathrm{Mg}_{2} \mathrm{~B}_{2} \mathrm{O}_{5}$ ceramic it is positive. The minimum value of formation energy for the doped $\mathrm{ZBO}$ system is $-4.5116 \mathrm{eV}$ ( $\mathrm{Zn} 2$ site), and the formation energy value of the $\mathrm{Mg} 1$ and $\mathrm{Mg} 2$ sites is the same. Hence, the $\mathrm{ZBO}$ system with the $\mathrm{Zn} 2$ site substitution is more stable, and $\mathrm{Zn} 2$ site is preferable and more likely to be occupied. The possibility of the Mg1 and Mg2 site to be occupied is equal, and the doping process of $\mathrm{Mg}^{2+}$ to the $\mathrm{ZBO}$ ceramic is more thermodynamically spontaneous than that of $\mathrm{Zn}^{2+}$ to the $\mathrm{Mg}_{2} \mathrm{~B}_{2} \mathrm{O}_{5}$ ceramic. The designed and measured total energy/mol for the $(1-\mathrm{x}) \mathrm{ZBO}+\mathrm{xMBO}(x=0.00-0.40)$ composite ceramics were obtained (the formation energy was not considered), as shown in Fig. 9(b). Both the designed and measured total energy/mol show an increasing trend. The former is larger than that of the latter for $\mathrm{x}=0.05-0.40$, and the system with relatively low energy is more stable and spontaneous to form. Hence, for the system with $\mathrm{x}>0.00$, the component fraction discrepancy between the designed and measured sample results from both the larger concentration of $\mathrm{Zn}^{2+}$ and lower total energy. These discussions further confirm the XRD refinements.

(a)

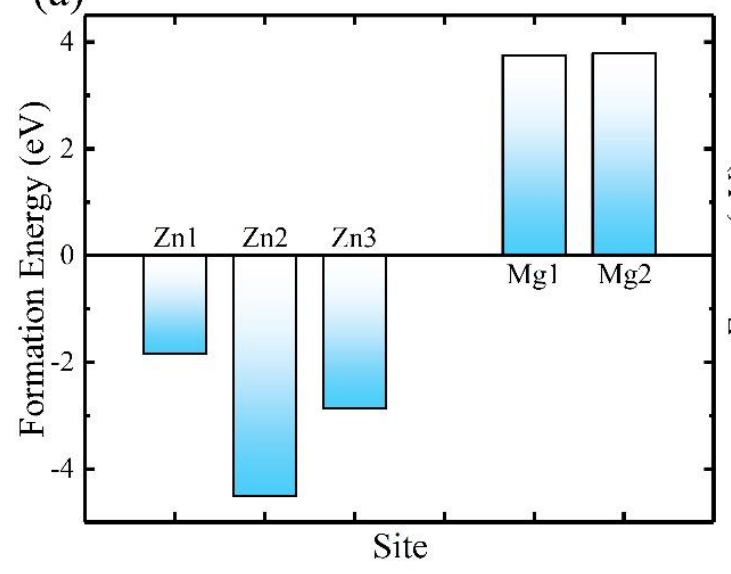

(b)

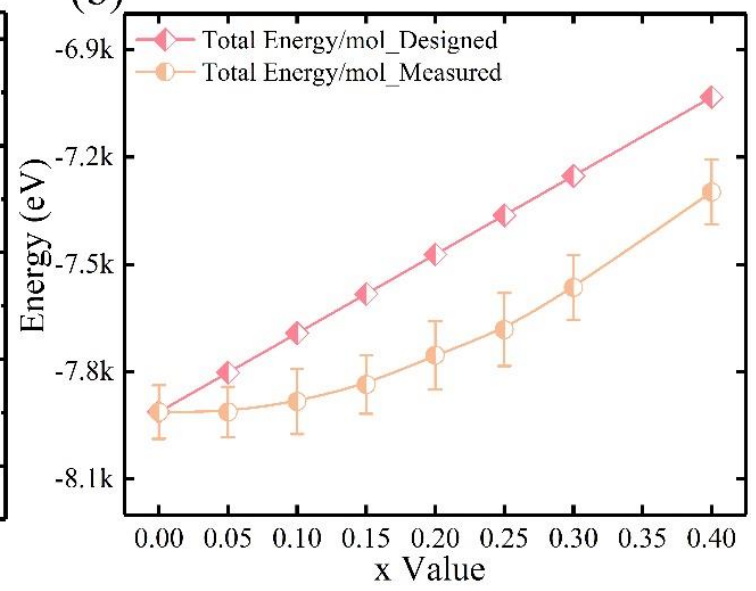

Fig. 9 Formation energy for doped-system of $\mathrm{ZBO}$ and $\mathrm{Mg}_{2} \mathrm{~B}_{2} \mathrm{O}_{5}$ ceramics (a), designed and measured total energy/mol of the $(1-\mathrm{x}) \mathrm{ZBO}+\mathrm{xMBO}(x=0.00-0.40)$ ceramics 


\section{Conclusion}

The sintering and microwave dielectric properties of the $\mathrm{Zn}_{3} \mathrm{~B}_{2} \mathrm{O}_{6}$ ceramic, with a large number of $\mathrm{Mg}^{2+}$ substitutions, have been researched profoundly using first principles calculations and solid-state reaction experiment. A solid solution containing three phases $\left(\mathrm{Zn}_{3} \mathrm{~B}_{2} \mathrm{O}_{6}, \mathrm{Mg}_{2} \mathrm{~B}_{2} \mathrm{O}_{5}\right.$, and $\left.\mathrm{ZnO}\right)$ was formed with mutual substitution $\left(\mathrm{Mg}^{2+}\right.$ and $\left.\mathrm{Zn}^{2+}\right)$. The bond parameters and electron distribution of the $\mathrm{ZnO}_{4}$ tetrahedron and the $\mathrm{MgO}_{6}$ octahedron have been modified. The sintering, substitution, and phase formation properties have been analyzed quantitatively through the energy parameters. Peak dielectric properties obtained when the sample with $\mathrm{x}=0.20$ was sintered at $950^{\circ} \mathrm{C}$, are $\varepsilon_{r}=6.47, Q \times f=89,600 \mathrm{GHz}$ (15.2GHz), $\tau_{f}=-48.6 \mathrm{ppm} /{ }^{\circ} \mathrm{C}$, and relative density $=96.7 \%$. The substitution of $\mathrm{Mg}^{2+}$ to $\mathrm{Zn}^{2+}$ is a feasible method to improve the microwave dielectric properties of the $\mathrm{Zn}_{3} \mathrm{~B}_{2} \mathrm{O}_{6}$ ceramic.

\section{Acknowledgements}

This work was supported by the Jiangxi Innovative Talent Program, Jiangxi Guochuang \& UESTC Joint R \& D Center Program (Grant No. H04W190371), and National Natural Science Foundation of China (Grant No. 61771104).

\section{Reference}

[1] Y. Lai, X. Tang, X. Huang, H. Zhang, X. Liang, J. Li, H. Su, Phase composition, crystal structure and microwave dielectric properties of Mg2-xCuxSiO4 ceramics, J. Eur. Ceram. Soc. 38 (2018) 1508-1516..

[2] W. Lei, Z. Zou, Z. Chen, B. Ullah, A. Zeb, X. Lan, W. Lu, G. Fan, X. Wang, X. Wang, Controllable tf value of barium silicate microwave dielectric ceramics with different Ba/Si ratios, J. Am. Ceram. Soc. 101 (2018) 25-30.

[3] D. Zhou, C.A. Randall, L. Pang, H. Wang, J. Guo, G. Zhang, X. Wu, L. Shui, X. Yao, Microwave dielectric properties of Li2WO4 ceramic with ultra-low sintering temperature, J. Am. Ceram. Soc. 94 (2011) 348-350. 
[4] S. Kweon, M. Joung, J. Kim, B. Kim, S. Nahm, J. Paik, Y. Kim, T. Sung, Low temperature sintering and microwave dielectric properties of B2O3-added LiAlSiO4 ceramics, J. Am. Ceram. Soc. 94 (2011) 1995-1998.

[5] S. Wang, X.B. Zhang, N-doped C@Zn3B2O6 as a low cost and environmentally friendly anode material for Na-ion batteries: high performance and new reaction mechanism, Adv. Mater. 31 (2019) e1805432.

[6] D.G. Chen, W.D. Cheng, D.S. Wu, H. Zhang, Y.C. Zhang, Y.J. Gong, Z.G. Kan, Syntheses, band structures and optical properties of Zn3B2O6 and KZn4B3O9, Solid State Sci. 7 (2005) 179-188.

[7] X. Wu, H. Wang, Y. Chen, D. Zhou, D. Suvorov, Synthesis and microwave dielectric properties of Zn3B2O6 ceramics for substrate application, J. Am. Ceram. Soc. 95 (2012) 1793-1795.

[8] U. Došler, M.M. Kržmanc, B. Jančar, D. Suvorov, A high-Q microwave dielectric material based on Mg3B2O6, J. Am. Ceram. Soc. 93 (2010) 3788-3792.

[9] S. Park, B. Magyari-Köpe, Y. Nishi, Electronic correlation effects in reduced rutile TiO2 within the LDA+U method, Phys. Rev. B 82 (2010).

[10] B.W. Hakki, P.D. Coleman, A dielectric resonator method of measuring inductive capacities in the millimeter range, Ire Trans. Microw. Theory Tech. 8 (2003) 402-410.

[11] C. Zhang, R. Zuo, J. Zhang, Y. Wang, J. Jones, Structure-dependent microwave dielectric properties and middle-temperature sintering of forsterite (Mg1-xNix)2SiO4 ceramics, J. Am. Ceram. Soc. 98 (2015) 702-710.

[12] H. Zhuang, Z. Yue, F. Zhao, J. Pei, L. Li, Microstructure and microwave dielectric properties of Ba5Nb4015-BaWO4 composite ceramics, J. Alloy. Compd. 472 (2009) 411-415.

[13] Y. Lv, R. Zuo, Y. Cheng, C. Zhang, P. Davies, Low-temperature sinterable (1-x)Ba3(VO4)2-xLiMg0.9Zn0.1PO4 microwave dielectric ceramics, J. Am. Ceram. Soc. 96 (2013) 3862-3867.

[14] Y. Wang, Y. Chen, S. Yao, C. Wu, Microwave dielectric properties of neodymium tin oxide, Ceram. Int. 40 (2014) 2641-2645.

[15] H. Yang, E. Li, S. Duan, H. He, S. Zhang, Structure, microwave properties and low temperature sintering of Ta2O5 and $\mathrm{Co} 2 \mathrm{O} 3$ codoped Zn0.5Ti0.5NbO4 ceramics, Mater. Chem. Phys. 199 (2017) 43-53.

[16] M. Valant, D. Suvorov, R.C. Pullar, K. Sarma, N.M. Alford, A mechanism for low-temperature sintering, J. Eur. Ceram. Soc. 26 (2006) 2777-2783.

[17] D. Zhou, F. Sun, Y. Hu, Q. Fu, G. Dou, Low-temperature sintering and microwave dielectric properties of Mg3B2O6-LMZBS composites, J. Mater. Sci-Mater. El. 23 (2011) 981-989.

[18] G. Dou, M. Guo, Y. Li, J. Lin, The effect of LMBS glass on the microwave dielectric properties of the Mg3B2O6 for LTCC, J. Mater. Sci-Mater. El. 26 (2015) 4207-4211.

[19] U. Došler, M.M. Kržmanc, D. Suvorov, The synthesis and microwave dielectric properties of Mg3B2O6 and Mg2B2O5 ceramics, J. Eur. Ceram. Soc. 30 (2010) 413-418.

[20] M. Kim, J. Lim, J. Kim, S. Nahm, J. Paik, J. Kim, K. Park, Synthesis of BaCu(B2O5) ceramics and their effect on the sintering temperature and microwave dielectric properties of $\mathrm{Ba}(\mathrm{Zn} 1 / 3 \mathrm{Nb} 2 / 3) \mathrm{O} 3$ ceramics, J. Am. Ceram. Soc. 89 (2006) 3124-3128.

[21] M. Ohashi, H. Ogawa, A. Kan, E. Tanaka, Microwave dielectric properties of low-temperature sintered Li3AlB2O6 ceramic, J. Eur. Ceram. Soc. 25 (2005) 2877-2881.

[22] X. Chen, W. Zhang, B. Zalinska, I. Sterianou, S. Bai, I.M. Reaney, C.A. Randall, Low sintering temperature microwave dielectric ceramics and composites based on Bi2O3-B2O3, J. Am. Ceram. Soc. 
95 (2012) 3207-3213.

[23] R. Peng, Y. Lu, Z. Tao, D. Chen, L. Shi, Q. Zhang, Y. Li, Improved microwave dielectric properties and sintering behavior of LiZnPO4 ceramic by $\mathrm{Ni2}+$-ion doping based on first-principle calculation and experiment, Ceram. Int. 46 (2020) 11021-11032.

[24] R. Peng, Y. Li, G. Yu, Y. Lu, S. Li, Effect of Co2+ substitution on the microwave dielectric properties of LiZnPO4 ceramics, J. Electron. Mater. 47 (2018) 7281-7287.

[25] R. Peng, Y. Li, H. Su, Y. Lu, Y. Yun, Q. Zhang, S. Zhang, Effect of cobalt-doping on the dielectric properties and densification temperature of Li2MgSiO4 ceramic: calculation and experiment, J. Alloy. Compd. 827 (2020) 154162.

[26] D. Thomas, M.T. Sebastian, Temperature-compensated LiMgPO4: a new glass-free low-temperature cofired ceramic, J. Am. Ceram. Soc. 93 (2010) 3828-3831.

[27] R. Peng, H. Su, D. An, Y. Lu, Z. Tao, D. Chen, L. Shi, Y. Li, The sintering and dielectric properties modification of Li2MgSiO4 ceramic with $\mathrm{Ni2}+-$ ion doping based on calculation and experiment, J. Mater. Res. Technol. 9 (2020) 1344-1356.

[28] Z. Cheng, X. Hu, Y. Li, Z. Ling, N. Alford, Fabrication and microwave dielectric properties of Mg2SiO4-LiMgPO4-TiO2 composite ceramics, J. Am. Ceram. Soc. 99 (2016) 2688-2692.

[29] G. Dou, D. Zhou, S. Gong, M. Guo, Low temperature sintering and microwave dielectric properties of Li2ZnSiO4 ceramics with ZB glass, J. Mater. Sci-Mater. El. 24 (2012) 1601-1607.

[30] T.S. Sasikala, C. Pavithran, M.T. Sebastian, Effect of lithium magnesium zinc borosilicate glass addition on densification temperature and dielectric properties of Mg2SiO4 ceramics, J. Mater. Sci-Mater. El. 21 (2009) 141-144.

[31] R. Umemura, H. Ogawa, H. Ohsato, A. Kan, A. Yokoi, Microwave dielectric properties of low-temperature sintered Mg3(VO4)2 ceramic, J. Eur. Ceram. Soc. 25 (2005) 2865-2870.

[32] R. Peng, Y. Li, Y. Lu, Y. Yun, W. Du, Z. Tao, B. Liao, High-performance microwave dielectric composite ceramics sintered at low temperature without sintering-aids, J. Alloy. Compd. 831 (2020) 154878.

[33] M. Guo, Y. Li, G. Dou, J. Lin, A new microwave dielectric ceramics for LTCC applications: Li2Mg2(WO4)3 ceramics, J. Mater. Sci-Mater. El. 25 (2014) 3712-3715.

[34] R.D. Shannon, Dielectric polarizabilities of ions in oxides and fluorides, J. Appl. Phys. 73 (1993) 348-366.

[35] G. Gouadec, P. Colomban, Raman Spectroscopy of nanomaterials: How spectra relate to disorder, particle size and mechanical properties, Prog. Cryst. Growth Ch. 53 (2007) 1-56.

[36] E.A. Barringer, The synthesis, interfacial electrochemistry, ordering, and sintering of monodisperse TiO2 powders, Massachusetts Institute of Technology, 1983.

[37] R. Lacomba, J. Ruiz, D. Errandonea, D. Martínez, A. Segura, Optical absorption of divalent metal tungstates: Correlation between the band-gap energy and the cation ionic radius, Europhys. Lett. 83 (2008) 37002.

[38] V.L. Gurevich, A.K. Tagantsev, Intrinsic dielectric loss in crystals, Adv. Phys. 40 (1991) 719-767. 
Figures

(a)

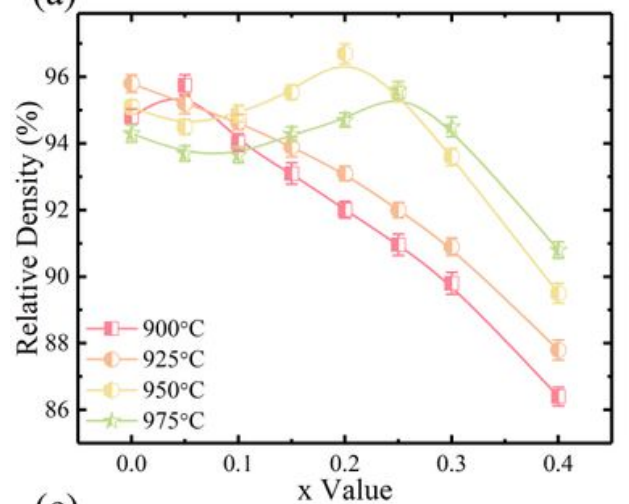

(c)

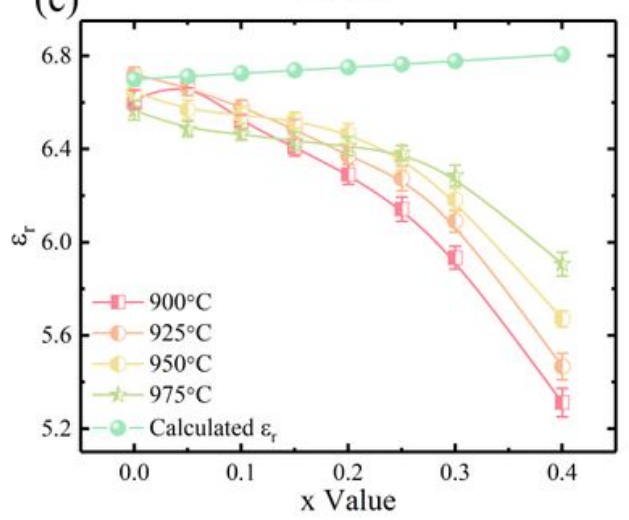

(b)

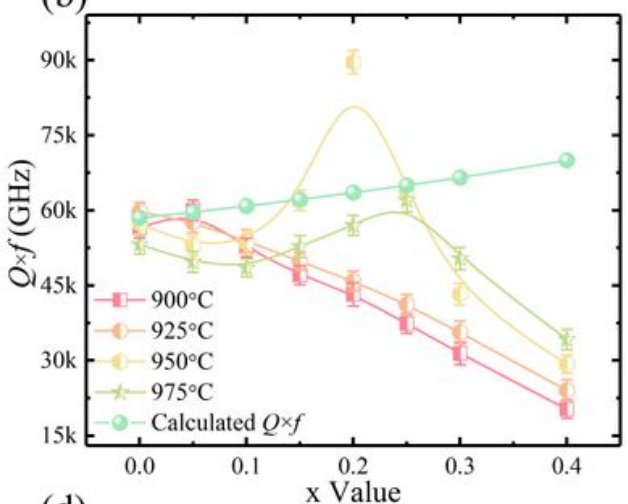

(d)

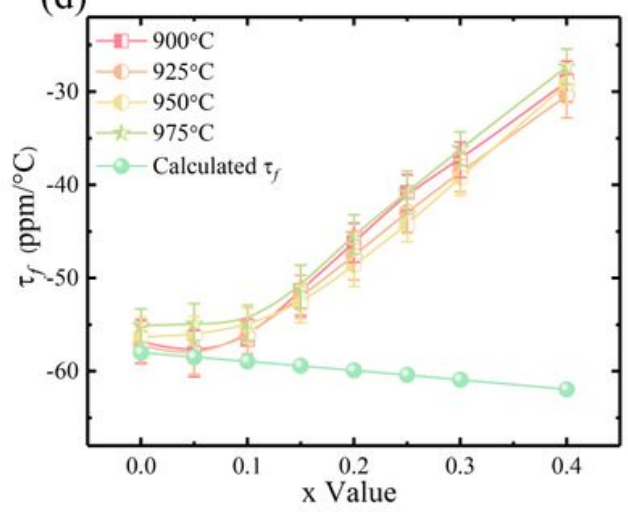

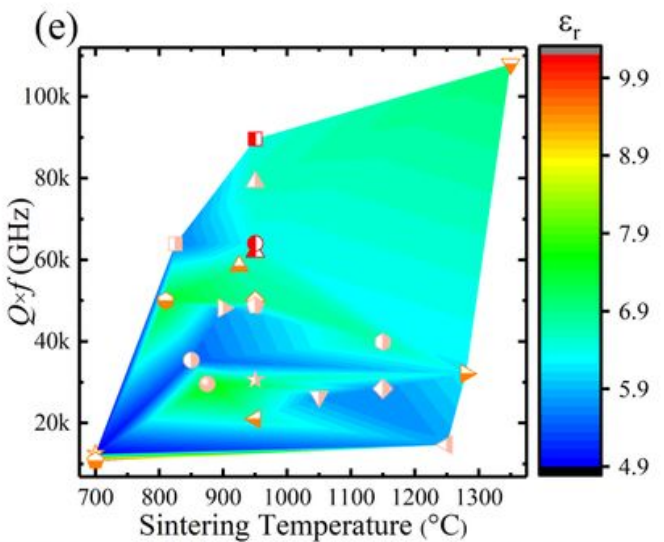

$\triangle$ This work $x=0.15$

D This work $x=0.20$

$\triangle \mathrm{Zn}_{3} \mathrm{~B}_{2} \mathrm{O}_{6}[7]$

- This work $x=0.25$

$\nabla \mathrm{Mg}_{3} \mathrm{~B}_{2} \mathrm{O}_{6}[8]$

$\triangleleft \mathrm{Mg}_{3} \mathrm{~B}_{2} \mathrm{O}_{6}+35 \mathrm{wt} \%$ LMBS [18] $\gg \mathrm{Mg}_{2} \mathrm{~B}_{2} \mathrm{O}_{5}[19]$

- $\mathrm{BaCu}\left(\mathrm{B}_{2} \mathrm{O}_{5}\right)[20]$

- $\mathrm{Bi}_{6} \mathrm{~B}_{10} \mathrm{O}_{24}[22]$

(1) $\mathrm{LiZn}_{0.93} \mathrm{Co}_{0.07} \mathrm{PO}_{4}[24]$

A. $\mathrm{LiMgPO}_{4}[26]$

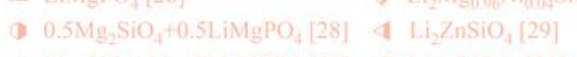

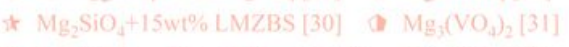

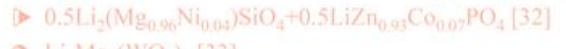

\section{Figure 1}

Relative density (a), Qxf (b), $\varepsilon r(c)$, and $\mathrm{tf}(\mathrm{d})$ values of the (1-x)ZBO+xMBO (x=0.00-0.40) ceramics sintered at different temperature; summary of sintering and dielectric properties of various ceramics (e) 
(a)

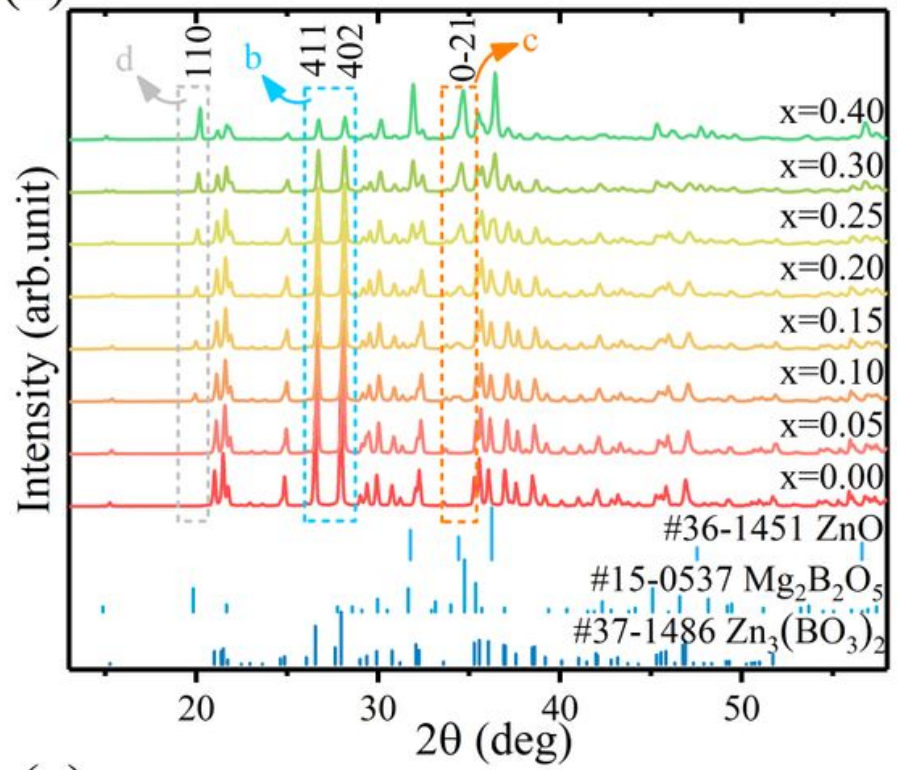

(e)

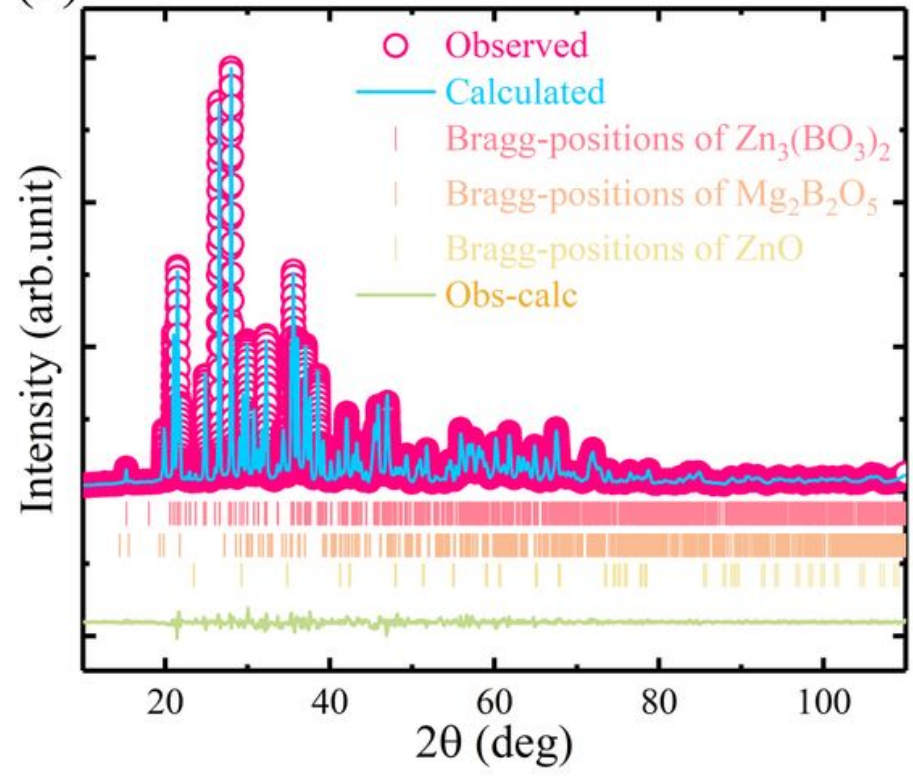

(b)

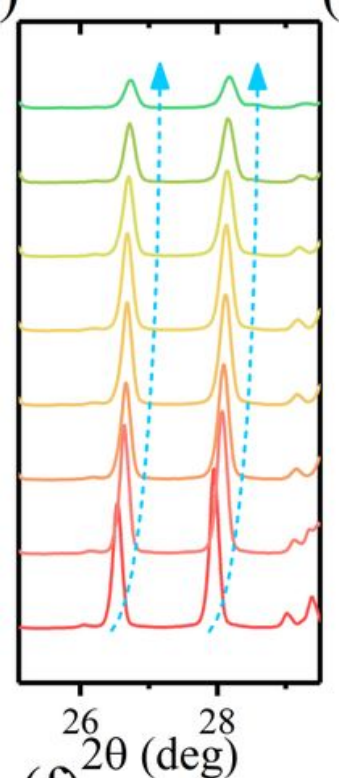

(c)

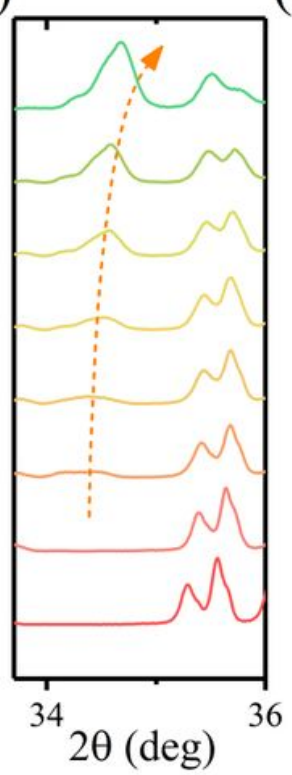

(d)

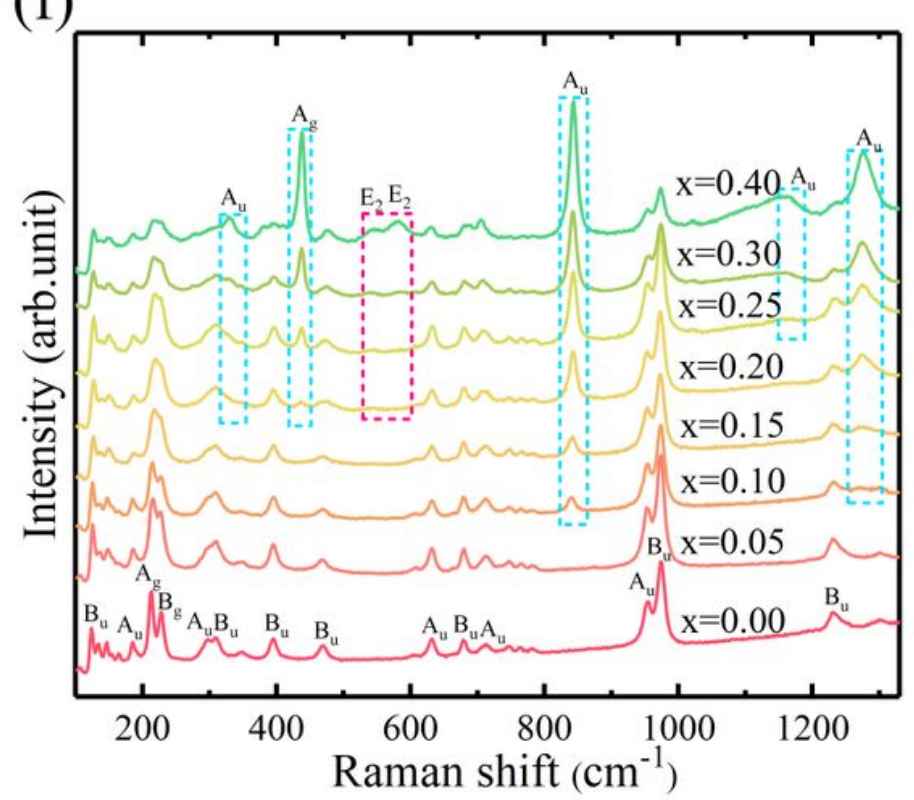

Figure 2

XRD patterns of the (1-x)ZBO+xMBO $(x=0.00-0.40)$ ceramics sintered at 950Х $(\mathrm{a}-\mathrm{d})$; experimental and calculated profiles of the $0.8 \mathrm{ZBO}+0.2 \mathrm{MBO}$ ceramic sintered at $950 \mathrm{Q}$ (e); Raman spectroscopy of the (1$\mathrm{x}) \mathrm{ZBO}+\mathrm{xMBO}(\mathrm{x}=0.00-0.40)$ ceramics sintered at 950囚 

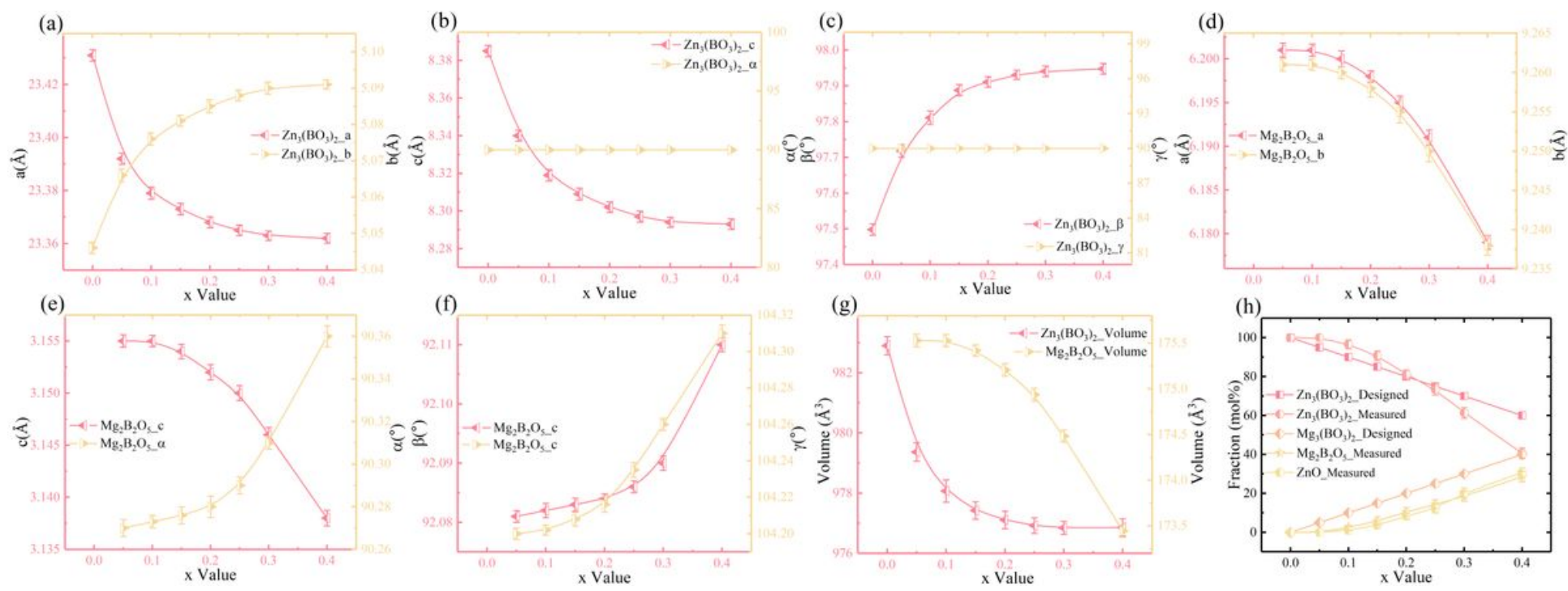

Figure 3

Lattice parameters of ZBO and Mg2B2O5 ceramics sintered at different temperature
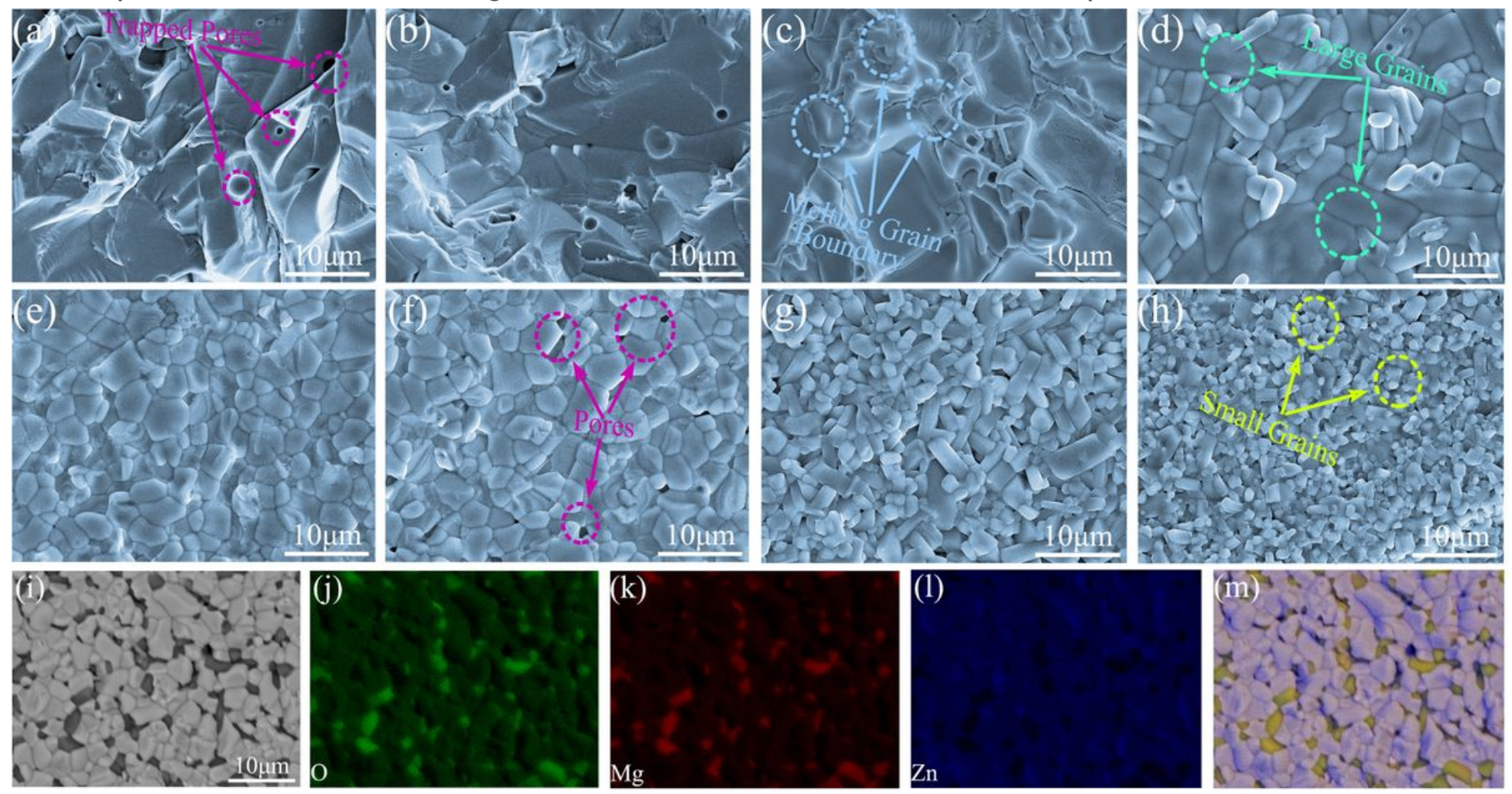

\section{Figure 4}

SEM micrographs of the (1-x)ZBO+xMBO $(x=0.00-0.40)$ ceramics sintered at 950冈 (a-h); EDS mapping images of the $0.8 Z \mathrm{BO}+0.2 \mathrm{MBO}$ ceramic sintered at $950 \otimes(\mathrm{i}-\mathrm{m})$ 
(a)

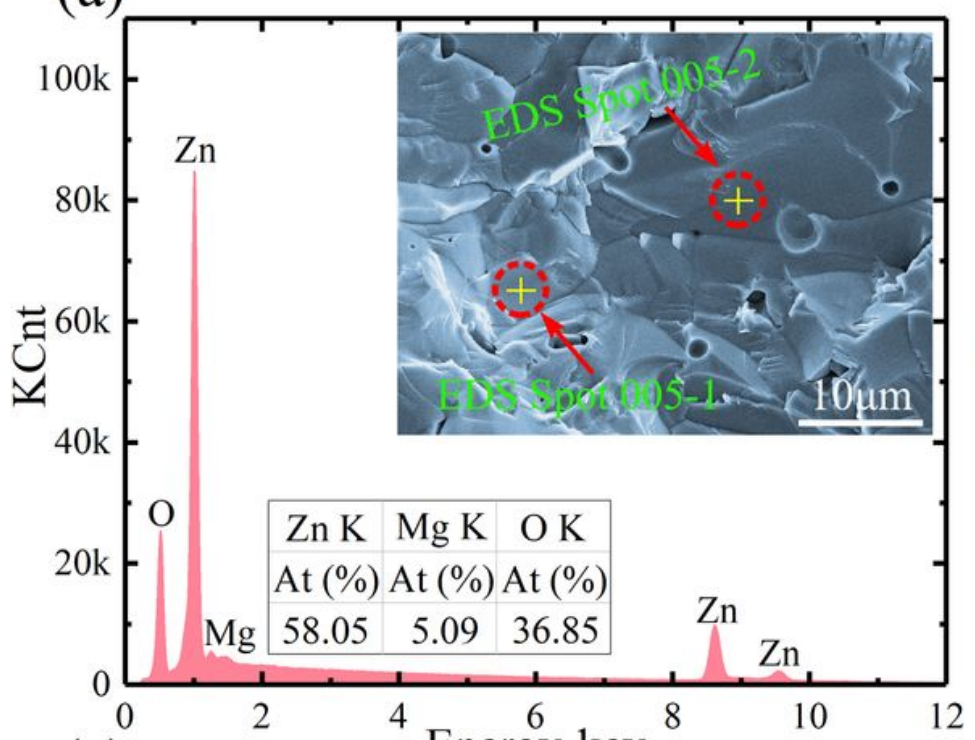

(c)

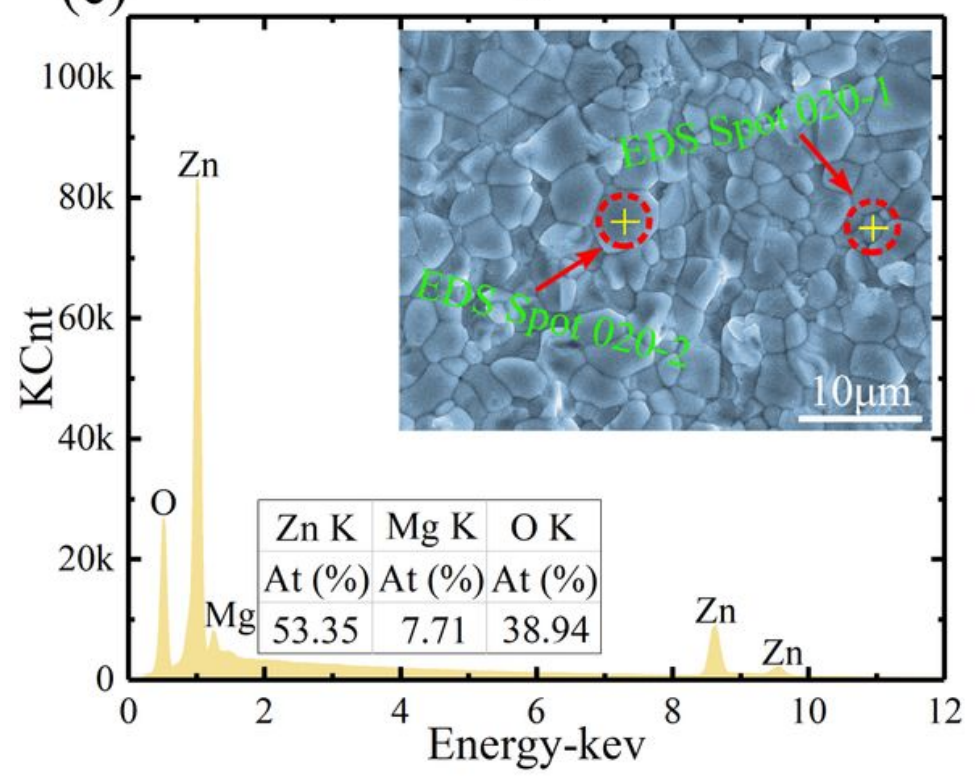

(b)

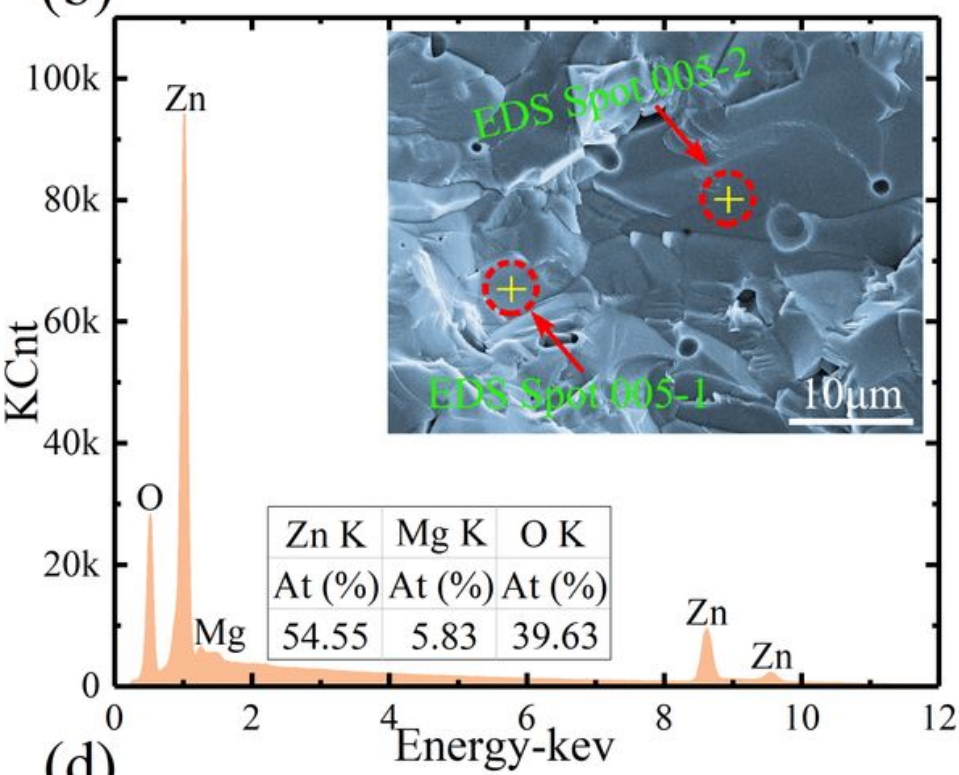

(d)

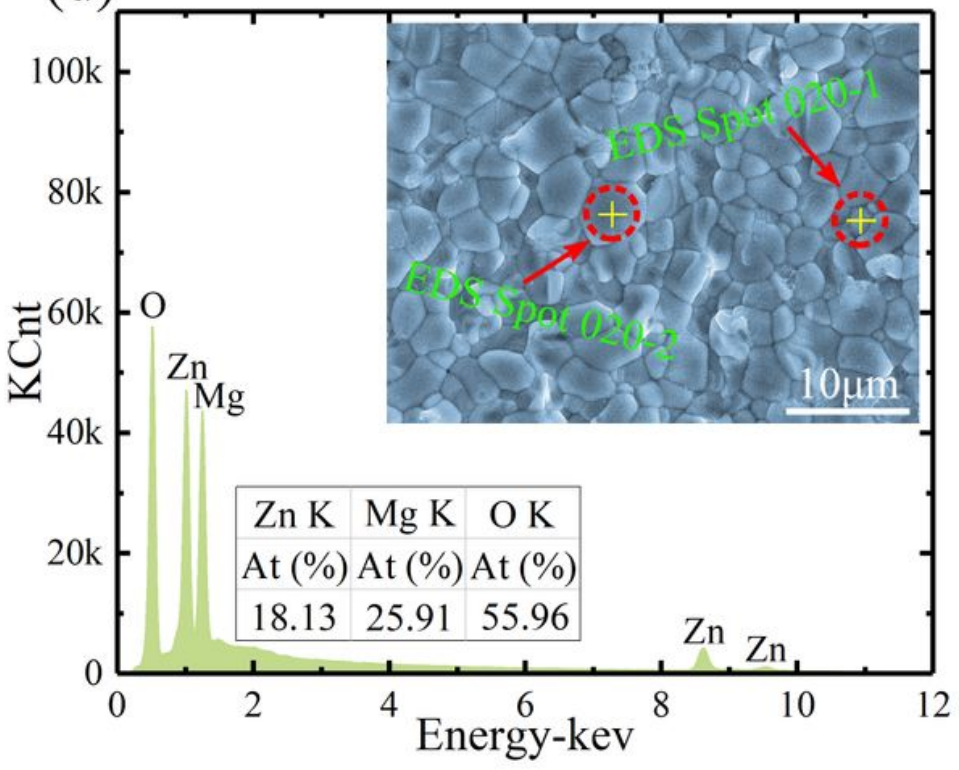

Figure 5

EDS result of the (1-x)ZBO+xMBO $(x=0.00-0.40)$ ceramics as $x=0.05(a, b)$ and $x=0.20(c, d)$ sintered at 950区 

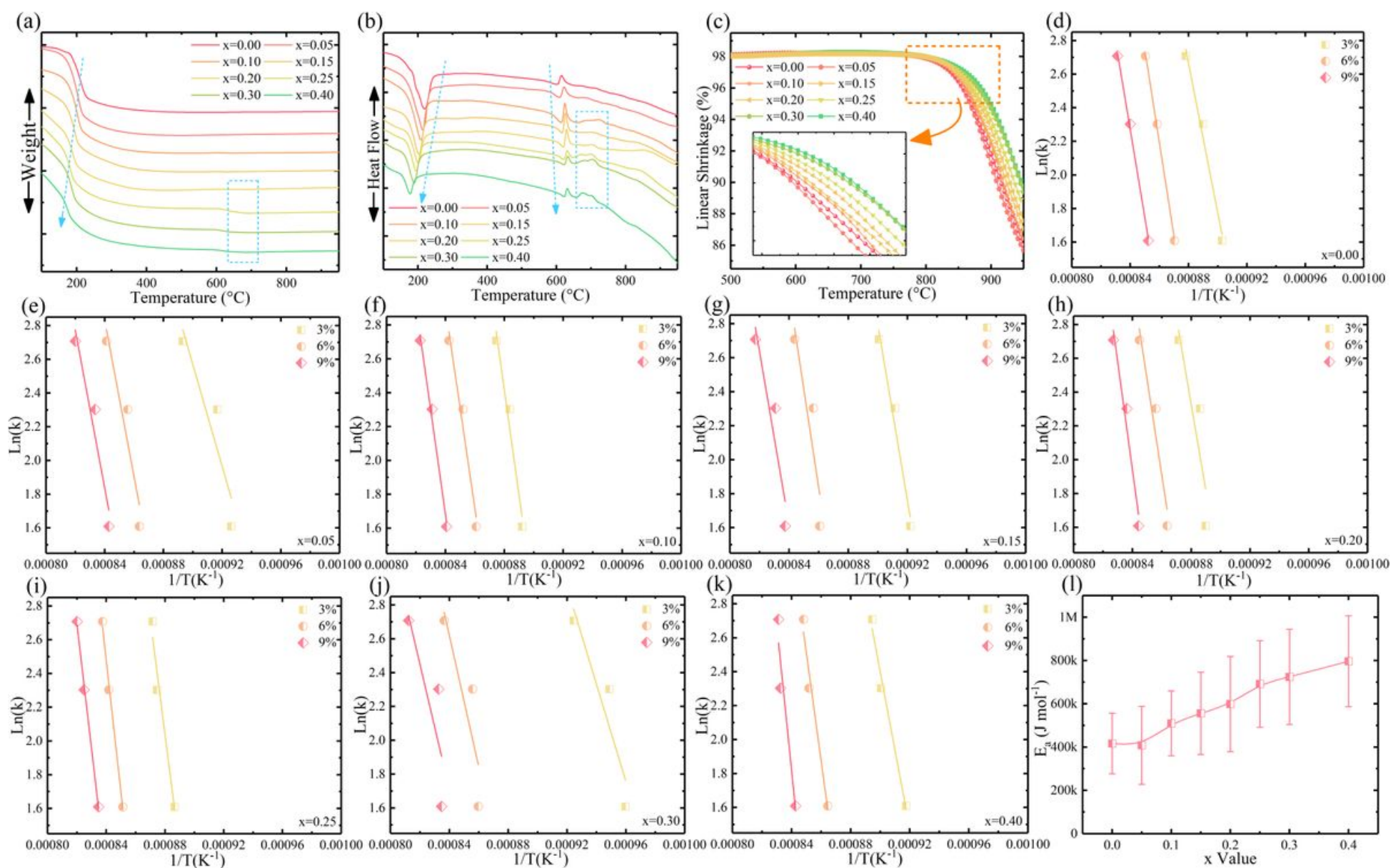

Figure 6

$\mathrm{TG}, \mathrm{DSC}, \mathrm{TMA}$ and sintering rate plotted against the inverse of temperature of the $(1-\mathrm{x}) \mathrm{ZBO}+\mathrm{xMBO}$ $(x=0.00-0.40)$ ceramics

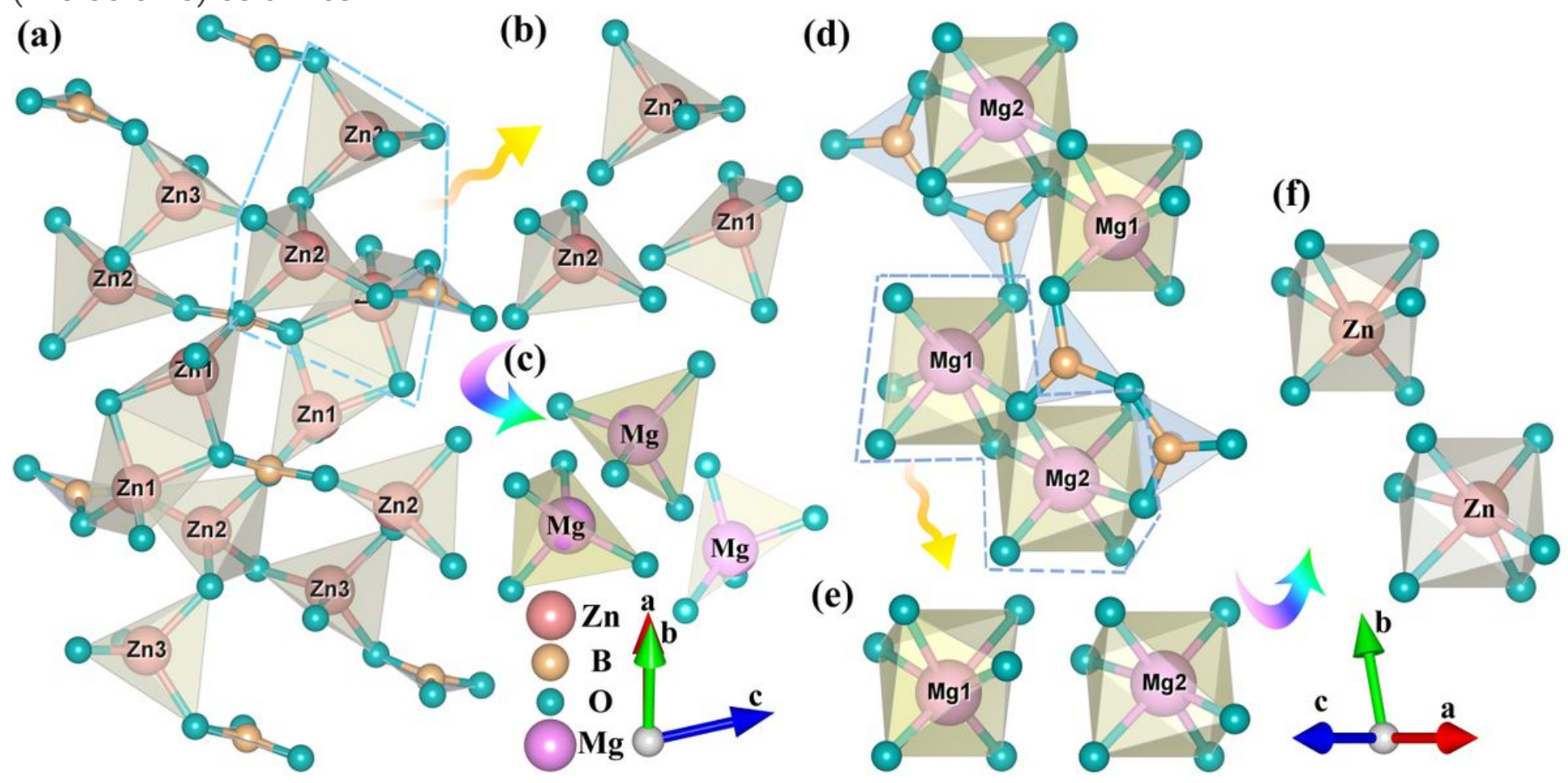




\section{Figure 7}

Crystal structure of ZBO (a); schematic diagram of ZnO4 tetrahedron before and after Mg2+ substitution (b-c); crystal structure of Mg2B2O5 (d); schematic diagram of MgO6 octahedron before and after Zn2+ substitution (e-f)
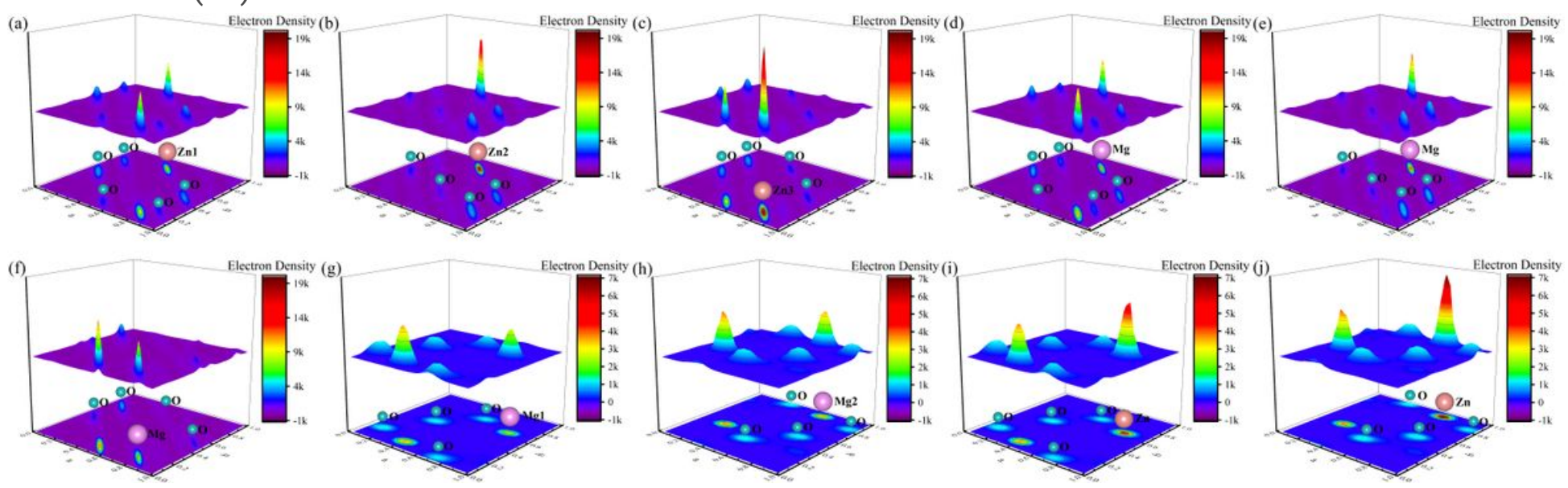

Figure 8

Electron density map of the plane with three kinds of $\mathrm{Zn2}+$ before (a-c) and after (d-f) Mg2+ substitution, and the plane with two kinds of Mg2+ before (g-h) and after (i-j) Zn2+ substitution

(a)

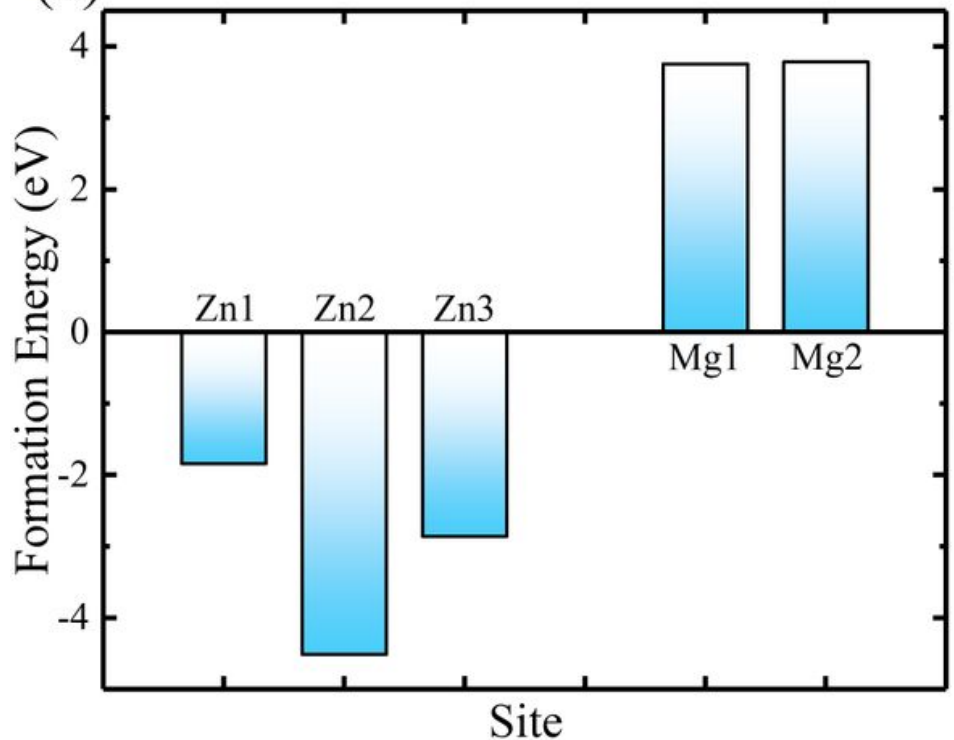

(b)

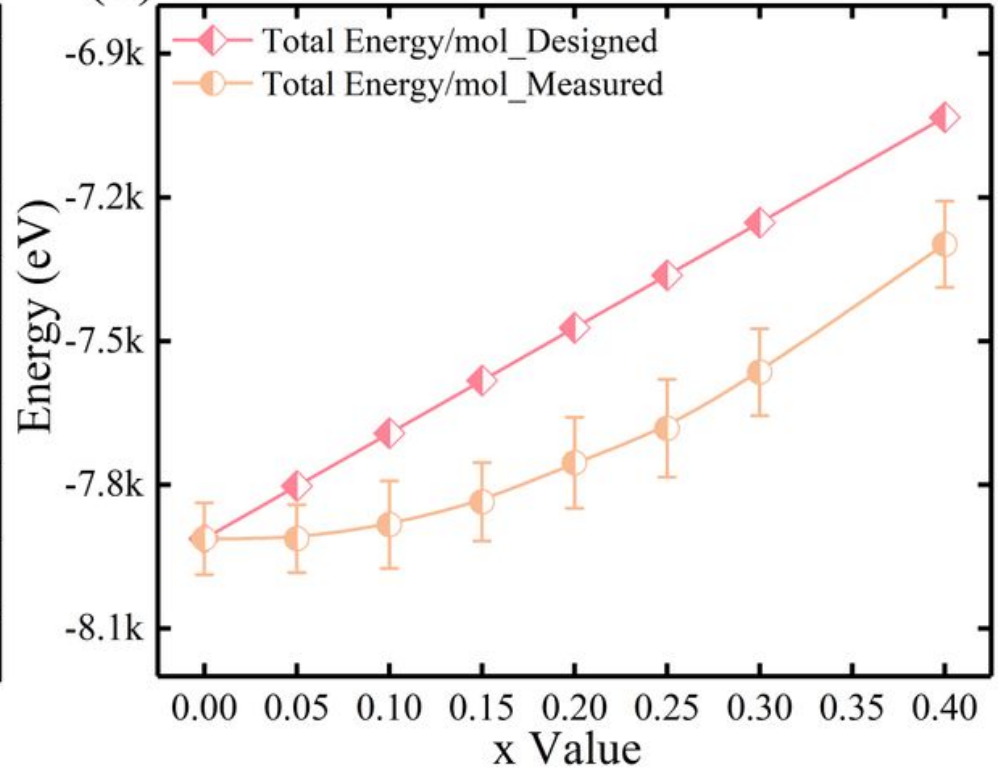

Figure 9

Formation energy for doped-system of ZBO and Mg2B2O5 ceramics (a), designed and measured total energy $/ \mathrm{mol}$ of the $(1-\mathrm{x}) \mathrm{ZBO}+\mathrm{xMBO}(\mathrm{x}=0.00-0.40)$ ceramics 